\title{
U.S. bank M\&As in the post-Dodd-Frank Act era: Do they create value?
}

\author{
by
}

\author{
George N. Leledakis* \\ Department of Accounting and Finance \\ Athens University of Economics and Business \\ Greece \\ and \\ Emmanouil G. Pyrgiotakis \\ Department of Accounting and Finance \\ Athens University of Economics and Business \\ Greece
}

This version: May, 2019

Journal of Banking and Finance, Forthcoming 2019

\footnotetext{
${ }^{*}$ Corresponding author: Department of Accounting and Finance, Athens University of Economics and Business, 76 Patission Str., 104 34, Athens, Greece; Tel.: +30 210 8203459. E-mail addresses: gleledak@ aueb.gr (G. Leledakis), manospirg@aueb.gr (E. Pyrgiotakis). We would like to thank Geert Bekaert (the Managing Editor), two anonymous referees, Kyriakos Chousakos, Manthos Delis, Vassilis Efthymiou, Athanasios Episcopos, Apostolos Katsafados, Dimitris Kyriazis, Emmanuel Mamatzakis, George Papaioannou, Leonidas Rompolis, Nickolaos Travlos, Nickolaos Tsangarakis, Andrianos Tsekrekos and the participants at the 2015 National Conference of the Financial Engineering and Banking Society (FEBS), the 2015 Hellenic Finance and Accounting Association Conference (HFAA), the 2016 ATHENIAN Policy Forum Conference (APF), the 2017 International Conference of the Financial Engineering and Banking Society (FEBS), and the 2017 European Financial Management Association Conference (EFMA) for their valuable comments and suggestions. Authors greatly acknowledge financial support received from the Research Center of the Athens University of Economics and Business (EP-2331-01 and EP-2256-01). All remaining errors and omissions are our own.
} 


\title{
U.S. bank M\&As in the post-Dodd-Frank Act era: Do they create value?
}

\begin{abstract}
We analyze the impact of the Dodd-Frank Act on the shareholder wealth gains using a sample of 640 completed U.S. M\&As announced between 1990 and 2014. Our results indicate a positive DFA effect on announcement period abnormal returns in small bank mergers. In fact, mergers with combined firm assets of less than $\$ 10$ billion create more shareholder value after the DFA, than ever before. This positive announcement effect in small deals appears to be linked with merger-related compliance cost savings and profitability improvements. By examining long-run abnormal returns, we find that the documented DFA effect on small deals announcement abnormal returns does not disappear overtime. Finally, we do not find such effects for non-U.S. bank M\&As over the same period.
\end{abstract}

JEL Classification: G14; G21; G28; G34

Keywords: Dodd-Frank regulation; Shareholder wealth; Event study; Financial performance 


\section{Introduction}

The Dodd-Frank Wall Street Reform and Consumer Protection Act (henceforth the DoddFrank Act or the DFA) was signed into law on July 21, 2010, marking a new epoch of financial regulation in response to the 2008 financial crisis. Historically, extensive federal regulatory reforms, such as the Riegle-Neal Act of 1994 and the Gramm-Leach-Bliley Act of 1999, had produced significant waves of bank mergers and acquisitions (M\&As). Therefore, if history repeats itself, we should expect an increase in bank merger activity after the enactment of the DFA.

We use merger data for 640 completed bank mergers announced between 1990 and 2014. We observe that small bank mergers experience an increasing trend after the DFA, while medium-sized and large deals have yet to reach the pre-crisis levels. We assume that this consolidation trend relates to a positive trade-off between synergies and the DFA regulation. In fact, banks with less than $\$ 10$ billion in assets are: (1) inclined to merge to cover the new regulatory compliance costs and (2) exempt from the majority of DFA regulations. In this case, market participants may perceive small bank mergers as value-creating investments. Thus, our main research question is whether the DFA has any effect on shareholder wealth gains in U.S. bank mergers, and if so, why.

To address our research question, we examine shareholder wealth effects for all 640 mergers and we break down the sample into two sub-periods (pre-DFA, post-DFA), and three asset-size categories (small, medium-sized, and large mergers). At a univariate level, we find that bidder and combined abnormal returns for small bank M\&As are significantly higher after the DFA, while in medium-sized and large deals, abnormal returns are not influenced by the Act's passage. Next, in order to compare changes across size groups between the two time periods, we conduct difference-in-differences regressions. In this empirical setting, small deals constitute the treatment group, since they are the ones affected by the reform, and 
larger deals are the control group. The results of this analysis provide conclusive evidence that the market response for small deals is significantly higher after the DFA compared to larger deals, even when we account for factors such as size, geographic diversification, and method of payment.

To ensure that our results are not driven by chance, we consider a series of robustness tests. First, we examine whether our inferences from the difference-in-differences analysis are sensitive to the "parallel" trends assumption. According to this assumption, abnormal returns for our treatment and control groups should follow parallel trends prior to the treatment (the DFA). Hence, in the spirit of Almeida et al. (2012), we repeat our differencein-differences models using hypothetical treatment periods from the pre-DFA years. The insignificant results of this falsification test suggest that the positive effect on small deals returns is isolated to periods occurring after the DFA's enactment.

We also account for the fact that deals announced before and after the DFA differ significantly in their firm- and/or deal-specific characteristics. To tackle this observed heterogeneity, we utilize a propensity score matching technique as in Alexandridis et al. (2017). Notably, our matching approach increases the magnitude of the reported DFA effect on small bank M\&As. On the contrary, the insignificant results for medium-sized and large mergers support our argument that deals above the $\$ 10$ billion mark can be a reliable control group in our empirical specification. We also repeat our difference-in-differences regressions using the propensity-matched observations, and we find results similar to our baseline regressions.

The second part of our research question refers to the possible explanations behind the positive DFA effect on small deals announcement period returns. We argue that under the new reform, small bank M\&As may be more profitable due to a positive trade-off between synergies and the DFA's regulatory burden. Therefore, we investigate whether small mergers 
after the DFA have realized any compliance cost savings and profitability improvements, and if so, whether these improvements are somehow related to abnormal returns.

At a first step, we examine the long-run performance of the merging firms of our sample, by comparing pre- and post-merger industry-adjusted financial ratios. Our analysis focuses on two profitability measures and three compliance costs indicators outlined by Cyree (2016). Our preliminary results indicate that after the DFA, the average small merging bank is more profitable and realizes significantly higher improvements in the cost of labor relative to the average small non-merging bank. At a second step, we use a difference-in-difference-indifferences approach, and find that after the DFA, small bank mergers outperform their larger counterparts, in terms of profitability and per-employee cost of labor. Further, we repeat this analysis using the propensity score matching approach. In most cases, comparing post-DFA deals with their pre-DFA matched counterparts increases the magnitude of the documented performance gains in small deals.

The most challenging part of this analysis is to find a link between compliance costs, profitability, and abnormal returns in small deals. Following the reasoning of Knapp et al. (2005), we assume that improvements in compliance costs may be positively related to profitability improvements. In this regard, we find that, after the DFA, small mergers are more profitable when they achieve significant savings in the per-employee cost of labor. Further, in the spirit of DeLong and DeYoung (2007), we examine the relation between changes in profitability and announcement period abnormal returns in small deals. Using a two-stage regression to address endogeneity concerns as in Dahya et al. (2019), we find that more profitable mergers experience higher announcement abnormal returns.

We present two additional robustness tests to ensure the stability of our results. First, if performance improvements are lower than expected, then it is likely that stock prices will be adjusted to this unfavorable news (Dutta and Jog, 2009). For this reason, we examine whether 
the positive DFA effect on small deals announcement returns is followed by a negative correction after the merger. Using the approach of Bessembinder and Zhang (2013), we find that bidders realize insignificant long-run abnormal returns during the two years after the merger, and thus, we assume that the positive effect of the DFA on the announcement period abnormal returns does not disappear overtime.

Second, if the documented improvement in small deals abnormal returns is indeed a DFA effect, then it should be evident only in the U.S. market. If this is not the case, then it is likely that this observed shift in investors' behavior relates to other potential influential factors such as international economic conditions or the passage of Basel III. Therefore, to account for this possibility, we collect a comparable sample of non-U.S. deals over the same period. Interestingly, the results indicate that outside the United States, stock markets do not react differently to the announcement of a small bank merger.

Our study is related to the extensive literature on U.S. bank M\&As. Cornett and De (1991), Houston and Ryngaert (1997), Becher (2000), DeLong (2003), DeLong and DeYoung (2007), and Brewer and Jagtiani (2013), among others, use the event study analysis to investigate the shareholder wealth effects associated with U.S. bank mergers. Collectively, these studies document a wealth transfer from bidder to target firm upon the announcement of the merger.

Our study is also related to the emerging literature that quantifies the impact of the DoddFrank Act on the U.S. financial sector. Balasubramnian and Cyree (2014), Akhigbe et al. (2016), and Gao et al. (2018) provide evidence consistent with the DFA's efficiency in addressing the too-big-to-fail (TBTF) problem. Focusing on small community banks, Cyree (2016) examines the cost of complying with the DFA regulations and finds that the compliance burden for small institutions is significantly increased after the Act's passage. 
Finally, Cumming et al. (2019) find that U.S. hedge funds realize lower alphas, after the implementation of the DFA.

Overall, we contribute to the existing literature in three ways. First, we provide a detailed analysis of the impact of the Dodd-Frank Act on the U.S. bank M\&As, and we analyze the different effect of the new legislation on small, medium-sized, and large banks, respectively. Second, we provide conclusive evidence that after the DFA, small bank M\&As create more shareholder value than their larger counterparts. Third, we find that after the DFA, small deals realize significant improvements in profitability and labor costs, and we link these improvements to the documented DFA effect on announcement period abnormal returns.

The remainder of the paper is organized as follows. Section 2 analyzes the key provisions of the DFA that are likely to affect bank merger activity for small, medium-sized and large banks, respectively. Section 3 details the data collection for the empirical analysis. Section 4 describes the methodology. Section 5 reports our main empirical results for the abnormal returns analysis. Section 6 examines the long-run performance of our sample deals, and links performance changes to abnormal returns. Section 7 conducts two main robustness tests to evaluate the consistency of our results. Section 8 concludes the paper.

\section{The legislation}

The Dodd-Frank Act is a massive piece of federal regulation (2,319 pages) designated to "promote the financial stability of the United States by improving accountability and transparency in the financial system, to end 'too big to fail', to protect the American taxpayer by ending bail-outs, to protect consumers from abusive financial services practices, and for other purposes." In line with the objective of this paper, we focus on the Act's provisions that are likely to impact the future of the U.S. bank M\&As.

In fact, the new financial reform legislation incorporates a plethora of sections governing bank mergers. The DFA imposes new concentration limits and barriers for banks planning to 
execute a merger. For example, Section 622 of the DFA prohibits a financial company from acquiring another institution if the combined firm would control more than $10 \%$ of the U.S.based aggregate liabilities of all the U.S. financial institutions. Additionally, Section 623 authorizes regulators not to approve a proposed merger transaction if the resulting depository institution would hold more than 10\% of all Federal Deposit Insurance Corporation's (FDIC) deposits. In practice however, it is unlikely that these concentration limits would deter further consolidation within the banking industry, because the average bank merger does not even approach these asset-size thresholds (Skeel, 2011).

At the same time, the DFA includes several provisions that do not directly address the bank M\&A issue, but could reshape the U.S. banking industry in such a way that consolidation might be inevitable. The new regulatory regime introduces specific asset-size cut-offs ( $\$ 10$ billion, and $\$ 50$ billion) and imposes strict reforms for banks that exceed these thresholds. All these reforms may provide motives or counter-motives for banks to grow larger through M\&As. At the later parts of this section, we analyze the DFA effect on the different groups of banks, as well as the possible relationship between the new legislation and bank merger activity in the U.S. Henceforth, we define small, medium-sized, and large banks (or mergers), as those banks with total assets (combined firms' assets) of less than $\$ 10$ billion, between $\$ 10$ billion and $\$ 50$ billion, and greater than $\$ 50$ billion, respectively.

\subsection{Small banks under the DFA}

Traditionally, federal regulation has been rather favorable to big banks, since the broad principles of financial regulation are the same for all banks, regardless of their size and activities. The Dodd-Frank Act attempts a shift from this "one-size-fits-all” approach by establishing specific asset-size thresholds tailored to benefit small banks in terms of regulatory reforms. As a matter of fact, the majority of the DFA's regulations include some form of exemption for small banks. Out of the 14 major DFA provisions, 13 either include an 
exemption for small banks or are tailored to provide these institutions with relief from specific regulations (Hoskins and Labonte, 2015).

At first glance, small banks seem to be unaffected from the passage of the Dodd-Frank Act. However, the DFA incorporates more than 500 separate rules and mandates governing all depository institutions. The implementation of such reforms is associated with increased compliance costs. Compliance costs are the costs the bank must bear in order to comply with the new regulations, such as: hiring suitable employees, shifting existing employees to regulatory compliance tasks, relying on outside compliance experts, time-consuming operations by non-specialized employees, etc. Recent empirical evidence suggests that the DFA is quite burdensome for small institutions in terms of compliance. Feldman et al. (2013) for instance, use data on employees and salaries' costs to proxy for regulatory compliance in small banks. They find that increases in employees and/or salaries relate to significant decreases in profitability. In this regard, the 2014 KPMG Community Banking Survey (Depman, 2014) indicates that $45 \%$ of community banks estimate compliance costs in the scale of $5-10 \%$ of total operating costs. In this survey also, employee expenses constitute a significant portion of the total compliance costs. Cyree (2016) estimates compliance costs for small U.S. banks around major crisis-based regulatory reforms, using measures of profit, labour costs, and productivity as indicators of regulatory compliance costs. His results suggest that the Dodd-Frank Act was the most burdensome reform for small banks, compared to previous regulatory changes. In a more recent survey, Dahl et al. (2018) report that compliance costs averaged $7 \%$ of non-interest expenses in small banks. The authors highlight that labour costs account for the vast majority of the reported compliance costs.

\subsection{Medium-sized banks under the DFA}

Under the Dodd-Frank Act, banks that exceed $\$ 10$ billion in assets are subject to a many activity-based restrictions. More precisely, Title X of the DFA requires the establishment of 
the Consumer Financial Protection Bureau (CFPB). The CFPB is an independent executive agency within the Federal Reserve, authorized to promote consumer financial protection. The new Bureau has unprecedented autonomy in issuing new rules and exclusive regulatory authority on consumer protection issues. The principal focus of the Bureau is to monitor mortgage and credit card-related issues in financial institutions with more than $\$ 10$ billion in assets. Title X also incorporates Section 1075, commonly known as the Durbin Amendment. Under this section, banks that exceed the $\$ 10$ billion threshold face a cap on debit card interchange transaction fees. Lastly, section 165 of the Act requires banks with total consolidated assets of more than $\$ 10$ billion to conduct annual stress tests to determine whether they have the necessary capital to absorb potential losses emanating from adverse economic conditions. Therefore, all these DFA provisions are applicable to medium-sized and large banks and they effectively single out small institutions.

\subsection{Large banks under the DFA}

For banks that exceed $\$ 50$ billion in assets, the DFA imposes even stricter regulatory requirements. Title I of the DFA establishes a new powerful regulatory body; the Financial Stability Oversight Council (FSOC). The main purpose of the FSOC is to identify potential risks to the stability of the U.S. financial system associated with large bank holding companies (BHCs) or non-bank financial companies. The Council focuses primarily on BHCs and non-bank financial institutions that hold more than $\$ 50$ billion in assets. The institutions that exceed this threshold are considered systemically important financial institutions (SIFIs), and are subject to increased prudential, capital, and liquidity standards. Hence, the DFA has provided an official asset-size threshold for a financial institution to be designated as systemically important or TBTF. 


\subsection{Merging activity and the DFA}

The DFA regulatory costs influence banks of all sizes, but in different ways. In relative terms, compliance costs are more burdensome to small banks, since these institutions have less capacity for regulatory compliance relative to their larger rivals. In fact, relative compliance costs increase as bank size decreases (Dahl et al., 2018). Consequently, it is likely that small banks will be inclined to merge in order to distribute these compliance costs over a higher output level. In this respect, Aiello and Tarbert (2010), and Marsh (2015) argue that the imposition of the DFA compliance costs on small banks would dictate these institutions to consolidate or go out of business. In accordance with these arguments, Peirce et al. (2014) surveyed 200 small banks in their study, and reported that more than $25 \%$ of these banks were contemplating M\&A strategies to adjust to the DFA compliance costs.

As mentioned above, the DFA has a different effect on medium-sized and large institutions. It is reasonably that medium-sized and large banks will commit fewer resources for regulatory compliance than small banks, as a proportion to their overall revenues. For this reason, these institutions might be less tempted to merge with the intention to spread the DFA compliance costs over a larger asset base. Moreover, under the Dodd-Frank Act, banks that exceed specific asset-size thresholds ( $\$ 10$ billion and $\$ 50$ billion respectively) are subject to enhanced prudential standards and activity-based restrictions, which are designated to limit their excessively risky (and highly profitable) activities. Contrary to compliance costs, the costs of these reforms could not be absorbed by getting larger, since the restrictions increase with size. Thus, as banks grow larger beyond the specified thresholds, the trade-off between synergies and the cost of regulation may not be particularly lucrative to provide these firms with additional incentives for M\&As. 


\subsection{The DFA effect on announcement period returns}

The stock market reaction at the announcement of a merger reflects the investors' perception about the value created or destroyed by the merger (DeYoung et al., 2009). Value-creating mergers should provide a positive trade-off between merger-related financial gains and costs. In this regard, the DFA may have benefited small bank mergers in two ways: (1) mergers between small banks may achieve significant economies of scale through compliance cost savings, and (2) banks with less than $\$ 10$ billion in assets are subject to many regulatory exemptions, which provide these institutions with a competitive advantage against their larger rivals. Following these arguments, we expect a positive trade-off between economies of scale and the cost of regulation for small bank mergers, and thus, we predict higher abnormal returns for these deals post-DFA. In contrast, we do not expect a similar effect on mergers between larger institutions because: (1) as banks grow larger, they have higher capacity for regulatory compliance (and thus they offer fewer opportunities for economies of scale), and (2) after the $\$ 10$ billion mark, activity-based restrictions increase with size. For these reasons, it is likely that any merger-related cost savings would be inadequate to offset the cost of the new regulations for medium sized, and especially for large institutions. Hence, we do not predict any significant improvements in announcement period abnormal returns for these deals.

\section{Sample description and statistics}

\subsection{Merger sample}

Our bank M\&As data is collected from the Thomson ONE database. Mergers are manually confirmed against the National Information Center (NIC) database. ${ }^{1}$ We use the following five criteria to obtain the initial sample:

\footnotetext{
${ }^{1}$ We make some corrections on the initial sample obtained by Thomson ONE database. For example, in the merger of Peoples Federal Bancshares, Inc. with Independent Bank Corp., Thomson ONE reports an incorrect acquirer. Following NIC, the correct acquirer is the Independent Bank Corp. (with ticker INDB) headquartered
} 
1. Both bidders and targets are commercial banks and savings institutions with a threedigit primary SIC codes equal to 602 and 603, respectively, or bank holding companies with a four-digit primary SIC code equal to $6712 .^{2}$

2. The announcement of the merger is between January 1, 1990 and December 31, 2014.

3. Both bidders and targets are U.S. public firms listed on NYSE, Amex, or Nasdaq.

4. The bidder acquired an interest of above $50 \%$ in a target, raising its interest from below $50 \%$ to above $50 \%{ }^{3}$

5. All deals are completed.

The criteria result in an initial sample of 670 bank mergers. From this sample we exclude 19 mergers, because stock return data were available on the Center for Research in Security Prices (CRSP) for either the bidder or the target firm, but the data ends before the announcement date. We also exclude 2 mergers due to the fact that both targets were incorrectly classified as publicly traded firms on the Thomson ONE database. ${ }^{4}$ In line with Hagendorff and Vallascas (2011), we also exclude 8 mergers which involved failing institutions, as reported by Thomson ONE (Cowan and Salotti, 2015). One additional merger was removed due to the fact that the bidder experienced extraordinary returns at the announcement date, distorting the calculation of the average abnormal returns. ${ }^{5}$ The final sample consists of 640 mergers, where 557 of the deals were announced in the pre-DFA period, and the remaining 83 mergers were announced after the Act's enactment on July 21 , 2010.

in Massachusetts. Thomson ONE reports the Independent Bank Corp. (with ticker IBCP) headquartered in Michigan as the acquiring firm.

${ }^{2}$ CommerceFirst Bancorp, Inc. has been assigned with a target primary four-digit SIC code of 6011 in the Thomson ONE database. NIC reports that the company operates as a BHC. We therefore include the merger of CommerceFirst Bancorp, Inc. with Sandy Spring Bancorp, Inc. in our sample.

${ }^{3}$ In line with the literature, we exclude leveraged buyouts, minority stake purchases, acquisitions of remaining interest, privatizations, recapitalizations, spin-offs, repurchases, exchange offers, and self-tender offers.

${ }^{4}$ Thomson ONE reports The Bancorp, Inc. (with ticker TBBK) headquartered in Delaware and Enterprise Bancorp, Inc. (with ticker EBTC) headquartered in Massachusetts as the target firms. Both reported institutions are listed on the Nasdaq. However, the actual deals involve two unlisted targets; The Bancorp, Inc., headquartered in Kentucky, and Enterprise Bancorp, Inc., headquartered in Florida.

${ }^{5}$ FNB United Corp. experienced an abnormal return of $60.07 \%$ on the announcement day. 


\subsection{Evolution of bank mergers overtime}

Figure 1 illustrates the evolution of U.S. bank M\&As from 1990 to 2014 for small, mediumsized, and large mergers respectively. During the 1990s, a period characterized by intense banking deregulation (Riegle-Neal Act of 1994, Gramm-Leach-Bliley Act of 1999), the U.S. banking industry underwent dramatic consolidation. As shown in the figure, the number of deals follows an upward trend in the first half of the decade for all three types of mergers. Notably, merger activity for small and medium-sized mergers skyrocketed in the late 1990s. In the early 2000s, the level of banking consolidation was slightly decreased, although the industry experienced a peak in M\&As deals in 2004. The bank merger activity then plummeted, as a result of the 2008 financial crisis.

Historically, regulatory intervention has been a chief motivation for consolidation within the banking industry. Interestingly, after the DFA's enactment in the end of 2010, we observe that the number of small bank mergers exhibits an increasing trend. Data for the medium-size mergers suggest that M\&As activity has started to rebound, despite the fact that the annual number of deals has yet to reach the pre-crisis levels. On the other hand, large bank mergers are on their lowest point since the late 1990s. Overall, as shown in Figure 1, small banks have become more acquisitive after the DFA.

\section{$\underline{\text { Insert Figure } 1 \text { here }}$}

\subsection{Summary statistics}

Table 1 illustrates the distribution of the merging firms' total assets at year-end prior to the merger announcement. We classify our sample into three categories based on our two size thresholds ( $\$ 10$ billion, and $\$ 50$ billion). Panels $\mathrm{A}$ and $\mathrm{B}$ partition the sample based on whether the merger was announced before or after the DFA. Further, we report summary statistics for the bidder, target and combined firm's total assets for both sub-periods. 
Before the DFA, $49.37 \%$ of bidding firms were below the $\$ 10$ billion mark (275 out of 557), while after the DFA, small bidders constitute the $73.49 \%$ of the sample (61 out of 83 ). The difference in proportions of small bidders between the two sub-periods is statistically significant at the $1 \%$ level, using a Chi-square test $\left(\chi^{2}=16.83\right)$. In both periods, small banks dominate the sample of target firms: $89.59 \%$ before the DFA (499 out of 557), and $95.18 \%$ after the DFA (79 out of 83). Small mergers in the pre-DFA period are less than half of the sample (255 out of 557 or $45.78 \%$ ), whereas in the post-DFA period, the majority of bank M\&As fall in the small-sized category (55 out of 83 or $66.27 \%$ ). Again, the difference in proportions of small mergers between the two sub-periods is statistically significant at the $1 \%$ level $\left(\chi^{2}=12.11\right)$. These findings reinforce our argument that small bank M\&As are more frequent corporate events after the Act's enactment.

\section{$\underline{\text { Insert Table } 1 \text { here }}$}

Table 2 displays summary statistics for our whole sample. We partition the sample based on whether the merger was announced before or after the Act's enactment. The last column of Table 2 reports differences in means and medians between these two sub-periods. Panel A of Table 2 illustrates the statistics for firm-specific variables. The dispersion of asset-size and return on assets (ROA) among bidders and targets is in line with the extant literature. The average bidder is substantially larger and more profitable than the average target both before and after the DFA. In addition, after the DFA, bidding banks are significantly smaller, while both bidders and targets are less profitable and better capitalized, which is consistent with the low-profitability environment of the post-crisis period and the increased capital requirements of the new regulatory regime.

Panel B of Table 2 provides descriptive statistics for deal-specific variables. Deal values in the post-DFA period are smaller by approximately $\$ 1$ billion, and the difference between the two sub-periods is statistically significant at $10 \%$ level. We also observe that on average, 
acquisition premiums do not differ after the DFA. Days to completion is the time interval between the announcement and the completion date, and serves as the proxy for merger complexity (Becher and Campbell, 2005). We find that deals in the post-DFA era took a significant longer time to be completed than deals announced before the Act's passage. We could offer several possible explanations for this latter finding. For example, due diligence process in the post-crisis years may be more time-consuming, due to increased opacity in target bank's assets. Alternatively, this difference may reflect the more stringent regulatory environment for bank M\&As in the post-DFA period. In terms of method of payment, stock financing was the prevailing choice before the DFA, while after the DFA, bidders prefer to pay with a combination of stock and cash. Lastly, the percentages of deals between banks that are headquartered in the same state suggest an equally divided distribution between intrastate and interstate mergers throughout the whole examination period.

\section{$\underline{\text { Insert Table } 2 \text { here }}$}

\section{Methodology}

We employ both univariate and multivariate approaches in order to investigate whether the DFA has altered the way market participants view U.S. bank M\&As: (1) we compute bidder, target, and combined cumulative abnormal returns around the announcement date for the whole sample of 640 mergers and for the two separate sub-periods (Pre-DFA, and PostDFA), and we breakdown these samples using two asset-size cutoffs ( $\$ 10$ billion, and $\$ 50$ billion), (2) we estimate single-differences and difference-in-differences (DD) regression models, to examine the effect of the DFA on announcement period returns, after controlling for firm- and deal- specific characteristics.

\subsection{Announcement abnormal returns}

We employ the standard event study methodology outlined in Brown and Warner (1985). We use the OLS method to estimate the parameters of the following market model: 


$$
R_{i, t}=a_{i}+\beta_{i} R_{m, t}+\varepsilon_{i, t}
$$

where the dependent variable $R_{i, t}$ is the daily market return for stock $i, R_{m, t}$ is the daily return on the CRSP NYSE/Amex/Nasdaq value-weighted index (with dividends), and $t=(-200$, -21) indexes days prior to the announcement of the merger. ${ }^{6}$ We estimate the daily abnormal returns for each firm as follows:

$$
A R_{i, t}=R_{i, t}-\left(\hat{a}_{i}+\hat{\beta}_{i} R_{m, t}\right)
$$

where $A R_{i, t}$ is the abnormal return for the firm $i$ on day $t, \hat{\alpha}_{i}, \hat{\beta}_{i}$ are the OLS estimates of the intercept and market beta coefficient, respectively. To construct the cumulative abnormal returns (CARs), we sum the estimated daily abnormal returns from one day before the announcement to one day after the announcement date. ${ }^{7}$ To calculate combined abnormal returns, we follow Houston and Ryngaert (1994), and we construct a hypothetical value weighted portfolio for each bidder-target pair ( $i=1$ to 640$)$ :

$$
\text { Combined } C A R=\frac{M V_{i}^{B} C A R_{i}^{B}+M V_{i}^{T} C A R_{i}^{T}}{M V_{i}^{B}+M V_{i}^{T}}
$$

where $M V_{i}^{B}$ and $M V_{i}^{T}$ are the market values of equity for the bidder and target $i$ five days before the merger announcement date, and $C A R_{i}^{B}$ and $C A R_{i}^{T}$ are the cumulative abnormal returns for each $i$ th bidder and target pair.

DeLong (2001) suggests that this static approach could severely under- or over-estimate the combined CARs, because changes in the market value of equity for each bidder-target pair may be asymmetric. To ensure robustness of our reported results we also employ her

\footnotetext{
${ }^{6}$ As a robustness check, we compute abnormal returns using the market adjusted return model, the mean adjusted returns model, and the market model with the Scholes-Williams beta estimation. We also repeat the analysis using the CRSP NYSE/Amex/Nasdaq equal-weighted index (with dividends) as the benchmark index. Finally, according to the literature, we use other estimation periods $(-300,-51)$ and $(-120,-31)$. The results obtained are similar to those presented.

${ }^{7}$ We also compute cumulative abnormal returns for other event windows ( -5 days to +1 days, -10 days to +1 days, and -10 days to +10 days). The results were similar.
} 
proposed methodology by constructing a hypothetical portfolio of the two merging firms and calculating its return as follows:

$$
R_{t}^{p}=\ln \left(\frac{M V_{i, t}^{B}+M V_{i, t}^{T}}{M V_{i, t-1}^{B}+M V_{i, t-1}^{T}}\right)
$$

where $R_{t}^{p}$ is the return of the hypothetical portfolio $p$ at day $t$, and $M V_{i, t}^{B}, M V_{i, t}^{T}, M V_{i, t-1}^{B}$ and $M V_{i, t-1}^{T}$ denote the market value of equity of bidder and target $i$ at days $t$ and $t-1$, respectively. Then, we use the return of the hypothetical portfolio (as it was a single firm) in equation (1) to estimate market model estimates, in order to compute its daily abnormal returns using equation (2). Both approaches produced qualitatively similar results.

Finally, to determine statistical significance, we use the standardized cross-sectional test of Boehmer et al. (1991). The test compensates for possible variance increases in abnormal returns, commonly found on event dates. Further, to account for the non-normal distribution of the security returns, we test the statistical significance of the estimated CARs by using a non-parametric test, the rank test outlined by Corrado (1989). This test has the advantage that makes inferences less sensitive to outliers.

\subsection{Difference-in-differences estimation}

The difference-in-differences approach is typically used to estimate the effects of specific policy interventions or policy changes (such as a passage of a law) on a group of people or firms that are directly treated by these changes (Lechner, 2011). In fact, the DD approach compares changes overtime in a group of subjects affected by the policy change to changes overtime in a group of subjects unaffected by the policy change, and attributes this "difference-in-differences" to the effect of the policy. The group that is affected by the policy change is referred to as "treatment group", and the unaffected group as "control group". Based on our research question, we presume that the treatment group in our case is the small bank M\&As, while the control group consists of both medium-sized and large mergers. 
To gauge the magnitude of the DFA on abnormal returns, we employ two different model specifications. In each specification, the dependent variable is the bidder, target, or combined three-day CARs, centered on the announcement date. In the first specification, we examine whether abnormal returns for the whole sample are improved after the DFA using a singledifferences approach:

$$
C A R_{i, t}=a+\beta_{1} D F A+\beta_{2} \text { Small }+\beta_{3} X_{i, t-1}+\beta_{4} Z_{i, t}+\varepsilon_{i, t}
$$

where $D F A$ is a dummy variable that equals 1 if the merger announcement day was after the DFA's enactment, and 0 otherwise, and Small is a dummy variable that equals 1 if the combined firms' consolidated assets are less than $\$ 10$ billion, and 0 otherwise. $X_{i, t-1}$ and $Z_{i, t}$ denote bank- and deal-specific variables, respectively (defined in the Appendix). ${ }^{8}$ In this specification, the coefficient of interest, $\beta_{1}$, measures whether abnormal returns are significantly changed after the DFA for the whole sample. We expect $\beta_{1}$ to be insignificant, since we assume that the DFA affects abnormal returns only in small deals.

In the second specification, we examine whether abnormal returns for our treatment group differ significantly from the abnormal returns of our control group after the DFA. This difference-in-differences approach is estimated using the following model:

$$
C A R_{i, t}=a+\beta_{1} D F A+\beta_{2} \text { Small }+\beta_{3} D F A \cdot \text { Small }+\beta_{4} X_{i, t-1}+\beta_{5} Z_{i, t}+\varepsilon_{i, t}
$$

In this specification, the interaction term between DFA and Small constitutes the DD estimator. Therefore, to address our research question, we expect to find a positive and statistically significant coefficient for $\beta_{3}$.

The advantage of this regression-based approach is that it allows us to compare CARs between comparison groups across time periods, while controlling for observable differences in firm- and deal-specific characteristics. As we show in Table 2, the characteristics of bidder and target banks differ significantly before and after the DFA. Therefore, controlling for

\footnotetext{
${ }^{8}$ All continuous variables are winsorized at $1 \%$ and $99 \%$ level. In all our models, we report heteroskedasticityrobust $t$-statistics.
} 
these differences gives us a more robust estimate for the potential impact of the DFA on announcement period abnormal returns.

\section{Main empirical results}

\subsection{Cumulative abnormal returns}

In this section, we report bidder, target, and combined firms announcement CARs for the whole sample of 640 mergers. Further, we partition the sample into small, medium-sized, and large bank mergers, and we investigate whether abnormal returns differ significantly before and after the Dodd-Frank Act. As is typical in the literature, we focus primarily on bidder and combined CARs, although we also report results for target firms.

Panel A of Table 3 reports results for the whole sample. Over the whole period, bidder and target announcement CARs are in line with the existing bank M\&As literature. Bidders experience negative and statistically significant abnormal returns, whereas targets experience positive and statistically significant abnormal returns, according to both the parametric and the non-parametric tests (Trifts and Scanlon, 1987; Hannan and Wolken, 1989; Cornett and De, 1991; Houston and Ryngaert, 1997; DeLong, 2003; DeLong and DeYoung, 2007). In addition, combined CARs for the whole period indicate a modest value creation in the scale of $0.90 \%$ (Becher, 2000). By looking at the next two columns of Panel A, we find that this pattern in abnormal returns persists both before and after the DFA. However, target and combined CARs are significantly higher after the Act's enactment.

Panels B, C, and D, report results for the sub-samples of small, medium-sized, and large mergers, respectively. In the pre-DFA period, bidder and target CARs in all three categories are in line with what reported for the whole sample. Combined CARs are positive and statistically significant in small deals, but insignificant in both medium-sized and large deals. In the post-DFA period, we document a substantial improvement in abnormal returns for small deals. Now, bidder CARs are indistinguishable from zero, which suggests that after the 
DFA, bidders in small mergers experience a mean $1.25 \%$ higher abnormal return, relative to the pre-DFA years. This mean difference between the two periods is statistically significant at the $10 \%$ level. Furthermore, combined CARs are also significantly higher after the DFA. In particular, combined CARs for the 55 small deals are $3.44 \%$, and statistically significant at the $1 \%$ level. In economic terms, this figure implies a shareholder value creation of $\$ 23.09$ million for the average merger. The difference between the two periods is in the order of $1.85 \%$, and statistically significant at the $1 \%$ level. On the contrary, results for medium-sized and large deals suggest that both bidder and combined CARs do not improve after the DFA. Finally, target firms in all cases (except large mergers) experience statistically higher abnormal returns after the passage of the Act.

\section{Insert Table 3 here}

The results of the univariate analysis are important in two ways. First, these findings provide preliminary evidence that abnormal returns in small bank M\&As are indeed significantly higher after the DFA. Second, the fact that medium-sized and large mergers are not affected by the passage of the legislation supports our conjecture that these deals can serve as the control group in our DD analysis.

\subsection{Difference-in-differences results}

In Table 4, we present the results of the single-differences and the difference-in-differences regression models. Models 1, 3, and 5 report the estimated coefficients of the singledifferences regressions (equation 5). We find that bidder and combined CARs are not affected by the passage of the law, a finding which supports our argument that the DFA does not influence returns in all types of deals. On the contrary, consistent with the univariate analysis, target CARs are approximately $10.3 \%$ higher after the DFA. Models 2, 4, and 6 report the results of the DD regressions (equation 6). We observe that the inclusion of the interaction variable significantly changes our results. Bidder and combined CARs in small 
bank mergers are significantly higher after the DFA, compared to larger deals. More precisely, bidders in small bank mergers experience a mean $2.2 \%$ larger abnormal return after the DFA, while combined CARs are also $1.9 \%$ higher. In both cases, the DD estimator is statistically significant at the 5\% level. These findings not only support the preliminary findings of the univariate analysis, but also indicate that comparing CARs between small and larger deals across the two sub-periods increases the magnitude of the DFA effect on small deals returns. Conversely, we do not find similar evidence for the target firms of our sample. As we have seen at the univariate level, target abnormal returns increase in both small and medium-sized mergers post-DFA. It is therefore reasonable that the DD estimator is not statistically significant in this case. Lastly, to ensure that our results are not driven by the choice of the examination period, we repeat the analysis with the examination period starting from 1995 or 2000. In both cases, the results remained unchanged.

A handful of our control variables bear statistically significant coefficients in our model specifications. We observe that equity payments translate to lower bidder and combined abnormal returns (Travlos, 1987). In addition, Relative Size is positively associated with combined CARs (Becher and Campbell, 2005; Brewer and Jagtiani, 2013). In the regressions of target abnormal returns, the coefficients for Relative Size and State are negative and statistically significant in both models (DeLong, 2003). Finally, less capitalized targets realize lower abnormal returns. This finding might imply that bidders pay lower premiums for targets with depleted levels of capital.

\section{Insert Table 4 here}

A possible concern is that the inclusion of the crisis period in the pre-DFA sub-sample might bias downwards abnormal returns for this period and inflate the DFA effect. For this reason, we repeat our analysis by excluding all deals announced from the third quarter of 
2007 until the first quarter of 2009 (Kuppuswamy and Villalonga, 2015). Our findings remain the same.

\subsection{Is the difference-in-differences estimator valid?}

One major concern about inferences from studies that use the DD methodology is whether the treated and control groups followed "common or parallel" trends prior to the treatment. In the post-treatment period, any difference between the two groups can only be assigned to the treatment if this "parallel trends" assumption holds (Roberts and Whited, 2013). In this regard, we should test whether abnormal returns between small and larger mergers followed similar trends prior to the DFA. To do so, we follow the approach of Almeida et al. (2012), and we re-run the DD regressions of equation (6) using data only from the pre-treatment period (pre-DFA). To replicate our empirical specification, we use several hypothetical treatment periods, and we expect the DD estimator to be insignificant in all cases.

Table 5 reports the DD estimated coefficients of equation (6) for the several variations in our empirical specification. In each row, we use a different hypothetical treatment period. For example, the first row reports the estimated DD coefficient from a model where the treatment period begins in 2006 and ends right before the DFA's enactment. The first hypothetical treatment period starts from 2006, in order to have a comparable number of treated observations with the actual post-DFA sample. The last two columns of Table 5 report the total number of deals in pre-treatment and post-treatment period, respectively. In all cases, the total number of observations equals 557. As in Table 4, the dependent variable in each model is the bidder, target, or combined three-day announcement CARs. In all specifications, the DD estimator is indistinguishable from zero, which suggests that abnormal returns in small bank mergers do not increase (or decrease) compared to larger deals, after each hypothetical treatment period. Based on these findings, it is difficult to assume that abnormal returns between small and larger mergers were following very different trends prior to the 
DFA. Certainly, this fact strengthens our argument that the observed change in market reaction towards small deals is more likely due to the DFA, as opposed to some alternative force.

\section{$\underline{\text { Insert Table } 5 \text { here }}$}

\subsection{CARs based on propensity score matching}

Roberts and Whited (2013) suggest that the inclusion of controls in a DD regression helps accounting for observable differences between comparison groups, and improves the validity of the DD estimator. However, as shown by Heckman et al. (1998), incorporating control variables in a regression does not always account for these differences in observable characteristics. One possible solution to this problem is the use of matching methods ( $\mathrm{Li}$ and Prabhala, 2007).

From the summary statistics reported in Table 2, we observe that post-DFA deals differ significantly from pre-DFA deals. Hence, to control more directly for these differences, we use a propensity score matching (PSM) technique, in the spirit of Alexandridis et al. (2017). This PSM approach finds similar matches of post-DFA deals to pre-DFA deals and then compares their abnormal returns. The similarity between the two sub-periods is based on firm- and deal-specific characteristics such as size, method of payment, and geographic diversification.

To implement the propensity score matching technique, we run several probit models to estimate the probability of each deal to be announced after the DFA (propensity score). We estimate a probit model for the whole sample of 640 deals, as well as for the three separate sub-samples, small, medium-sized, and large mergers, respectively, in order to compare the results of the PSM analysis with the univariate results of Table 3. In these models, we use all 
the control variables of Table $4 .{ }^{9}$ After estimating the propensity scores, we match the deals using the nearest neighbor matching approach (one-to-one). ${ }^{10}$ Finally, we compare the difference in mean CARs between deals announced after the DFA and their PSM-matched pre-DFA counterparts. This difference is commonly referred to as the average treatment effect on the treated (ATT).

Panel A of Table 6 presents the results of the probit models. Model 1 presents the results for the whole sample. We observe that several variables are significant in determining the probability for a deal to be announced after the DFA. Actually, post-DFA deals are less likely to be geographically-focused and financed entirely with cash. In line with previous findings, small deals are more likely events after the DFA. In addition, post-DFA deals are more likely to be materialized over a longer time period, and target firms after the DFA tend to be more capitalized. By breaking down the sample based on our asset-size cutoffs, we obtain different results. For instance, in small post-DFA deals, bidders are more likely to be larger than their pre-DFA counterparts, while in medium-sized deals, we find the opposite result. Further, small deals after the DFA are more likely to be financed with a combination of cash and stock, and medium-sized deals after the DFA are less likely to be intrastate. In both cases, target capitalization is positively-related to the probability of being a post-DFA deal. Lastly, in all three sub-samples, Days to Completion bears a positive and statistically significant coefficient.

Panel B of Table 6 reports the ATTs produced by the propensity score matching technique. Initially, for the whole sample, only target abnormal returns are significantly higher after the DFA. However, in the small mergers sub-sample, the PSM approach produces compelling results. In fact, bidder CARs are now $3.22 \%$ higher after the DFA, a

\footnotetext{
${ }^{9}$ We exclude Roadiff from the probit model, because its inclusion worsens the quality of matching between preDFA, and post-DFA deals.

${ }^{10}$ As in Alexandridis et al. (2017), we also match using more than one nearest neighbors, as well as using the Gaussian kernel matching approach. In each case, we match both with and without replacement. All methods produce virtually identical results. The reported results are based on matching with replacement.
} 
difference which is statistically significant at the $1 \%$ level. Target and combined CARs are also significantly higher after the DFA. Their differences are equal to $15.52 \%$ and $3.75 \%$, respectively (both statistically significant at the $1 \%$ level). Notice that all three differences are substantially higher from what reported on Table 3. Therefore, the findings of the PSM analysis indicate that small bank mergers after the DFA outperform very similar deals from the pre-DFA period. In contrast, the evidence for the medium-sized and large mergers is similar to what reported at the univariate level, since bidder and combined CARs do not differ before and after the DFA. These results suggest that deals above the \$10 billion mark are untreated by the DFA, and thus, they comprise a credible control group for our DD analysis.

\section{Insert Table 6 here}

It is worth mentioning that the consistency of the PSM methodology depends on its ability to balance the distribution of the potentially confounding characteristics between the comparison groups. In untabulated analysis, we compare mean values between post-DFA deals and their pre-DFA matched counterparts for the whole sample, as well as for the three separate subsamples. We do not find any significant differences in means, which suggests that groups being compared are adequately balanced.

Moving a step further, we replicate our DD analysis of Table 4 using propensity-matched deals in the spirit of Almeida et al. (2012). Given that the results of the PSM analysis confirm that only small deals are influenced by the DFA, we use the same treatment and control groups as in the original DD analysis. Hence, we match the post-DFA observations of our treatment and control groups with their pre-DFA counterparts, utilizing the controls reported in Table 6. Then, we estimate again equations (5) and (6) using the propensity-matched 
observations as the pre-DFA sub-sample. ${ }^{11}$ We identify 68 unique, matched observations from the pre-DFA period, since matching is done with replacement. ${ }^{12}$ Table 7 reports noteworthy results. In fact, the matched-DD estimator suggests that bidder and combined CARs in small deals are now $3.4 \%$ and $3.2 \%$ higher after the DFA, compared to larger deals. In view of these results, we argue that the documented DFA effect on small deals returns should be relatively robust, since the PSM technique accounts for the self-selection bias associated with deals' propensity to be announced after the DFA.

\section{$\underline{\text { Insert Table } 7 \text { here }}$}

\section{The DFA effect on performance}

In our analysis so far, we have established that abnormal returns in small bank mergers are significantly higher after the DFA. Market returns however are forward-looking measures of the expected merger gains, and as such, they do not capture the actual changes in financial performance over longer horizons. At this point therefore, it is still questionable whether small bank M\&As have indeed resulted in performance improvements, and if so, whether these improvements are somehow related to the documented DFA effect on announcement period abnormal returns. The goal of this section is to address these concerns by finding a link between compliance costs, profitability, and abnormal returns in small bank mergers.

\subsection{Performance changes around $M \& A s$}

Initially, we measure the long-run change in the overall financial performance of the merging banks, using two profitability indicators: pre-tax ROA and pre-tax ROE (Houston et al., 2001). Further, we also examine merger-related improvements in performance by analyzing changes in several compliance costs indicators, using data on salaries and loans. Decreases in the cost of labor and increases in the loan output are associated with lower compliance costs (Cyree, 2016). For the cost of labor, we use two measures: average pay (Pay), which is

\footnotetext{
${ }^{11}$ We use controls in the matched-DD specification to account for differences between small and larger deals. Without their inclusion, we obtain similar results.

${ }^{12}$ Matching with no replacement produced virtually identical results.
} 
defined as total salaries to total number of employees, and salaries-to-assets ( $\mathrm{Sal}$ ). Total loans are also scaled by the number of employees (Loan). We conjecture that significant changes in these compliance costs indicators may have an impact on the post-merger financial performance of the merging firms.

In line with DeLong and DeYoung (2007), we follow a four step procedure to estimate changes in performance of the merging banks. First, to measure pre-merger performance, we collect data on the performance variables for both bidders and targets at the year-end prior to the merger announcement. Then, we combine these data for a hypothetical combined bank, and we calculate hypothetical pre-merger performance as the weighted average of values for each bidder-target pair. The weights are the relative sizes of the two merging banks at yearend prior to the merger announcement, as measured by the book value of assets (Cornett et al., 2006). Second, we measure post-merger performance as the performance of the actual combined bank two calendar years after the pre-merger performance year (Houston et al., 2001). ${ }^{13}$ Third, to account for industry trends, we adjust pre- and post-merger performance to the same-year mean performance of non-merging banks (Cornett et al., 2006). ${ }^{14}$ Non-merging banks are also classified into small, medium-sized, and large banks. Hence, the industryadjusted performance is the difference between the performance of the merging banks of a size category and the performance of the non-merging banks of the same size category. Fourth, we compute the change in performance as the difference between the post-merger industry-adjusted performance and the pre-merger industry-adjusted performance. ${ }^{15}$

\footnotetext{
${ }^{13}$ We repeat the same procedure for three years after the pre-merger performance year. The results are similar, but we lose 37 observations ( 32 in the pre-DFA period, 5 in the post-DFA period) due to unavailability of data.

${ }^{14}$ Non-merging banks of the pre-DFA (post-DFA) period are those banks that did not engage in mergers before (after) the DFA. For robustness, we also define non-merging banks of the year $t$ as those banks that did not engage in mergers from the year $t-1$ to the year $t+1$. The results are similar.

${ }^{15}$ From the whole sample of 640 mergers, we lose 56 observations due to the fact that some bidders went bankrupt after the merger, or they became acquisition targets. From the remaining 584 deals, we obtain data for either 584 observations (pre-tax ROA, pre-tax ROE, and Sal) or 378 observations (Pay and Loan). The difference between the two sets of variables is due to the lack of data for the number of employees.
} 
In Table 8, we report changes in all industry-adjusted performance indicators around merger announcements. Next, we compute differences in these changes in two dimensions. First, we estimate the differences in performance changes for each asset-size category across the two time periods. We do this to quantify the DFA effect on performance in each separate type of mergers (small, medium-sized, and large mergers). Second, we estimate the differences in performance changes between small and larger deals in either the pre- or the post-DFA period. This difference is a DD estimate, and tests whether the changes in performance differ significantly between small and larger deals in either the pre- or the postDFA period. The difference of the DD estimate of the post-DFA period minus the DD estimate of the pre-DFA period constitutes a difference-in-difference-in-differences (DDD) estimate. The DDD estimate allows us to simultaneously compare the changes in performance between small and larger deals across the two time periods, and as such, it shows the effect of the DFA on the performance changes of the two groups.

Panel A of Table 8 reports mean changes in overall financial performance for each size category. As we can see in column (2), the DFA has a positive effect on the small merger financial performance. In fact, profitability in small deals is significantly higher after the DFA both in terms of pre-tax ROA and pre-tax ROE. This means that the average small merging bank improves its profitability after the DFA more than the average small nonmerging bank. On the contrary, in medium-sized deals, $\triangle$ pre-tax ROA is significantly decreased after the DFA, while $\triangle$ pre-tax $R O E$ is negative and significant both before and after the DFA, albeit the difference between the two periods is insignificant. The results for large deals do not indicate any significant difference between the two periods. Furthermore, the DD estimate of column (5) suggests that in the pre-DFA period, both small and larger (both medium-sized and large deals) mergers realize virtually the same changes in profitability, while in the post-DFA period, small bank mergers outperform larger deals. As a 
result, the DDD estimate of column (6) indicates that after the DFA, small bank mergers are significantly more profitable compared to larger deals.

Panel B of Table 8 reports changes in the industry-adjusted compliance costs indicators for each size category. Interestingly, $\triangle P a y$ is significantly decreased after the DFA in small mergers, which suggests that small bank mergers realize higher savings in their per-employee cost of labour relative to the small non-merging banks. In medium-sized deals, the difference in $\triangle P a y$ between the two periods is insignificant, while large deals exhibit a significant increase in the cost of labour. During the pre-DFA period, $\triangle P a y$ is significantly higher for small deals compared to larger deals. In the post-DFA period though, this difference disappears. Subsequently, the DDD estimator is negative and significant, suggesting that after the DFA, small bank mergers realize higher improvements in the per-employee cost of labour, relative to larger deals. $\triangle S a l$ is also significantly decreased during the DFA period in small deals. However, medium-sized mergers also realize significant decreases in the salaries-to-assets ratio in that period, a fact that justifies the insignificant coefficient of the DDD estimator. Finally, the results for $\Delta$ Loan do not indicate any significant change in loan output after the DFA in any size category. Hence, the DDD estimator in this case suggests that the per-employee loan output does not increase or decrease in small deals after the DFA, relative to their larger counterparts. Although this finding might raise concerns regarding the drivers behind the improved profitability in deals below the $\$ 10$ mark, it is likely that the higher profits depend on factors unrelated to traditional lending activity. For example, the special treatment for small banks under the DFA (described in Section 2) may have boosted revenues from other sources, such as debit and/or credit cards.

\section{$\underline{\text { Insert Table } 8 \text { here }}$}

The results of this analysis are important in two ways. First, we document that after the DFA, the average small merging bank outperforms the average small non-merging bank, in 
terms of profitability and cost of labour. Second, we find that the post-DFA improvements in profitability and per-employee cost of labour in small deals are significantly higher relative to larger deals. These findings suggest that small bank M\&As after the DFA do not only create shareholder value, but they also result in significant improvements in performance. However, one possible limitation of this analysis is that it does not control for observable differences in characteristics between comparison groups and time periods. For this reason, we extend this analysis using a regression-based approach.

\subsection{Difference-in-difference-in-differences regressions}

In line with Morse (2011) and Tsoutsoura (2015), we also use DDD regression models to gauge the magnitude of the DFA on merger-related changes in performance. In these models, we incorporate control variables to account for heterogeneity across firm- and deal-specific characteristics. Hence, we estimate the following specification:

$$
\Delta y_{i, t+1, t-1}=a+\beta_{1} D F A+\beta_{2} \text { Small }+\beta_{3} D F A \cdot \text { Small }+\beta_{4} X_{i, t-1}+\beta_{5} Z_{i, t}+\varepsilon_{i, t}
$$

where $\Delta y_{i, t+1, t-1}$ is the difference of the performance variable y (pre-tax ROA, pre-tax ROE, Pay, Sal, Loan) defined as the post-merger industry-adjusted performance minus the premerger industry-adjusted performance, $X_{i, t-1}$ and $Z_{i, t}$ represent bank- and deal-specific variables, respectively (defined in the Appendix). In this specification, the key coefficient of interest, $\beta_{3}$, measures the impact of the DFA on the industry-adjusted performance of small bank mergers.

Panel A of Table 9 reports the results of the DDD analysis. ${ }^{16}$ Markedly, our findings not only complement those presented in Table 8 but also increase their magnitude. In both columns (1) and (2), the DDD estimator is strongly significant with a coefficient of 0.005 and 0.081, respectively. The magnitude of its coefficients suggests that the merger impact on pre-

\footnotetext{
${ }^{16}$ The number of observations in each model is decreased due to the inclusion of Bid Premium in the DDD regressions (539 instead of 584, and 353 instead of 378). We obtain similar results even if we do not include this control variable in our model specifications.
} 
tax ROA (pre-tax ROE) in small mergers is $0.5 \%(8.1 \%)$ higher after the DFA, compared to larger deals. Similarly, decreases in the cost of labour (as measured by $\triangle$ Pay), are significantly higher for small bank M\&As after the DFA. Finally, in line with what reported in Table 8, the DDD estimator is columns (4) and (5) are insignificant.

One possible concern with the DDD analysis arises if the assignment to the treatment is not random, meaning that the observed change in the outcome of interest is a function of difference in characteristics, rather than a treatment effect (Tsoutsoura, 2015). Hence, to control more directly for the observable differences between deals announced before and after the DFA, we again utilize the PSM approach (Dehejia and Wahba, 2002). Panel B of Table 9 compares changes in performance between post-DFA deals and their pre-DFA matched counterparts. Consistent with our previous results, we find that small deals after the DFA outperform very similar deals from the pre-DFA period, in terms of profitability and cost of labour. Then, we estimate equation (7) using propensity-matched deals, instead of the pre-DFA sub-sample. ${ }^{17}$ Panel $\mathrm{C}$ reports the results of this analysis. Notably, the matching approach strengthens the magnitude of the DDD estimators reported in Panel A.

\section{Insert Table 9 here}

\subsection{Compliance costs and profitability}

Knapp et al. (2005) examine the relationship between changes in post-merger profitability and changes in post-merger performance ratios. Following their approach, we investigate whether the profitability improvements in small mergers after the DFA are to any extent explained by the changes in our compliance costs indicators. To do so, we estimate the following model:

\footnotetext{
${ }^{17}$ Contrary to DDD regressions, matched-DDD regressions have equal number of observations in each specification. This happens because we have data for all variables for 81 post-DFA deals. By using Bid Premium as control in the probit model we have 76 observations. Then, we match with replacement and we obtain 59 pre-DFA matches. Our results do not differ if we match without replacement or if we exclude Bid Premium from the probit model
} 


$$
\begin{aligned}
& \Delta \text { Profitability }_{i, t+1, t-1}=a+\beta_{1} D F A+\beta_{2} \text { Small }_{+} \beta_{3} \Delta \text { Compl }_{i, t+1, t-1}+\beta_{4} D F A \cdot \text { Small } \\
& +\beta_{5} \text { DFA } \cdot \Delta \text { Compl }_{i, t+1, t-1}+\beta_{6} \text { Small } \cdot \Delta \text { Compl }_{i, t+1, t-1} \\
& +\beta_{7} \text { DFA Small } \cdot \Delta \text { Compl }_{i, t+1, t-1}+\beta_{8} X_{i, t-1}+\beta_{9} Z_{i, t}+\varepsilon_{i, t}
\end{aligned}
$$

where $\triangle$ Profitability ${ }_{i, t+1, t-1}$ is the difference in the profitability indicators (pre-tax ROA, pre$\operatorname{tax} R O E$ ) defined as the post-merger industry-adjusted profitability minus the pre-merger industry-adjusted profitability, and $\Delta \operatorname{Compl}_{i, t+1, t-1}$ is the difference in the compliance cost indicators (Pay, Sal, Loan) defined as the post-merger industry-adjusted compliance costs minus the pre-merger industry-adjusted compliance costs. The coefficient of interest, $\beta_{7}$, measures the extent to which changes in compliance costs impact profitability in small bank M\&As after the DFA.

Table 10 presents the results of this analysis. The first three columns report regressions where the dependent variable is the change in pre-tax ROA, and the last three columns report regressions where the dependent variable is the change in pre-tax ROE. In line with what we reported so far, the interaction variable between $D F A$ and Small is positive and statistically significant in all cases, suggesting that profitability in small bank M\&As is significantly improved after the DFA. In examining the causes behind this improvement, we observe that the coefficient of interest is negative and statistically significant at the 5\% level in both columns (1) and (4). This finding indicates that in small bank mergers, the documented decreases in the per-employee cost of labour are associated with higher profitability after the DFA. Therefore, we argue that changes in this compliance cost indicator can explain a significant part of the improved financial performance of small deals post-DFA.

\section{$\underline{\text { Insert Table } 10 \text { here }}$}

In sum, only $\triangle P a y$ is a significant determinant of profitability improvements in small deals post-DFA. For this reason, we recognize that our findings on the effect of compliance costs savings on post-merger profitability should be interpreted with caution. 


\subsection{Profitability and abnormal returns in small $M \& A s$}

Although we find a compelling improvement in profitability of small bank M\&As after the DFA, it is questionable whether this improvement is to any extent related to announcement period abnormal returns. In an efficient market, investor expectations about merger-related improvements in financial performance should be impounded in the announcement period abnormal returns (Fama, 1998). In this regard, the higher abnormal returns in small deals may be a simple projection of the future profitability improvements. To test this prediction, we could estimate the following cross-sectional regression as in DeLong and DeYoung (2007):

$$
C A R_{i, t}=a+\beta_{1} \Delta \text { Profitability }{ }_{i, t+1, t-1}+\beta_{2} X_{i, t-1}+\beta_{3} Z_{i, t}+\varepsilon_{i, t}
$$

However, endogeneity concerns may arise if we simply regress abnormal returns on changes in profitability. In fact, $\Delta$ Profitability $_{i, t+1, t-1}$ may be endogenously determined in equation (9), since profitability in small bank mergers has significantly increased due to the DFA's passage, and this increase may translate to higher abnormal returns. Therefore, to isolate the exogenous component of profitability, we instrument $\triangle P r e-t a x$ ROA and/or $\triangle P r e-$ $\operatorname{tax} R O E$ with the post-DFA indicator, and we employ a two-stage least squares regression in the spirit of Dahya et al. (2019). The documented increase in profitability after the DFA suggests that the DFA indicator satisfies the relevance condition of a valid instrument. In addition, we argue that the DFA impacts abnormal returns through its effect on profitability changes, fact that satisfies the exclusion criterion. The idea is that the DFA provides opportunities for profitability improvements in small deals, and as a result, market participants react more favorably to the merger announcement. For the remainder of this section, our discussion focuses on small bank M\&As, since the DFA effect on returns and financial performance is evident only in this sub-sample. ${ }^{18}$

\footnotetext{
${ }^{18}$ We repeat the analysis for the sub-samples of medium-sized and large mergers as well as for the larger subsample (both medium-sized and large deals). We do not find any evidence of a significant relation between abnormal returns and profitability changes.
} 
Table 11 reports the results of the two-stage OLS regressions for the sub-sample of small bank M\&As. The dependent variable on the first-stage regressions is either the $\triangle$ Pre-tax ROA or $\triangle$ Pre-tax ROE. In the second-stage regressions, the dependent variable is either the bidder or combined CARs, and the changes in profitability are based on their expected values of stage one. The positive and highly statistically significant coefficient of the DFA in the firststage regressions suggests that the DFA dummy is indeed a valid instrument for the changes in profitability. The results of the second-stage regressions indicate a positive and statistically significant relationship between abnormal returns and changes in profitability. Collectively, our results support the view that the merger-related improvements in profitability can explain the higher abnormal returns of small deals after the DFA.

To ensure the robustness of our results, we also perform weak instrument tests using firststage F-statistics. To reject the weak instrument assumption, the first-stage F-statistics should be greater than a critical value, which in our case equals 8.96 (Stock and Yogo, 2005). Therefore, we report two different first-stage F-statistics: (1) the Craig-Donald F-statistic, and (2) the Kleibergen-Paap F-statistic, which is more appropriate with the use of heteroskedasticity-consistent standard errors. We find that both F-statistics are higher that the critical value, fact which suggests that the $D F A$ is a relevant instrument.

\section{$\underline{\text { Insert Table } 11 \text { here }}$}

\section{Further robustness checks}

We conduct two main robustness tests to evaluate the consistency of our results. First, we examine whether the documented announcement period returns fully reflect the market's perception towards a proposed merger by examining long-run stock returns. More precisely, as the literature suggests, we test if there are any significantly negative long-run abnormal stock returns after the merger. In this case, it is likely that the positive DFA effect on small bank M\&As is reversed over time and disappears. Second, we collect a comparable sample 
of non-U.S. bank M\&As, and we examine the stock market reaction around the announcement of these deals. Given that the new legislation impacts only U.S. banks, we expect that the DFA effect will be evident only in the U.S. sample. Otherwise, it is also likely that the change in market reaction for small bank mergers relates to other factors rather than the Dodd-Frank Act itself.

\subsection{Does the DFA effect reverse in the long-run?}

In the previous section of this study, we assume that the market is efficient in incorporating the publicly available information in the merging firms' stock prices. More precisely, we propose that the announcement period abnormal returns should provide an unbiased estimate of the merger-related synergies on the acquiring firms' stockholders wealth (Moeller et al., 2004). If this is not the case, it is likely that the market will correct its short-term misreaction in a longer horizon (Masulis et al., 2007). In our case, if profitability improvements of small deals are lower than expected, then, the significantly higher announcement period abnormal returns for these deals may be reversed by a negative reaction after the merger (Rau and Vermaelen, 1998). To examine this possibility, we estimate long-run abnormal stock returns for the bidding banks of our post-DFA sub-sample, using the approach outlined by Bessembinder and Zhang (2013).

In order to estimate the long-run abnormal stock returns, we need to identify a matching firm for each bidding firm of our post-DFA sub-sample. In the spirit of Loughran and Ritter (1995) and Barber and Lyon (1997), each matching firm is defined as the bank with the closest book-to-market (BTM) ratio among firms with market capitalization between $70 \%$ and $130 \%$ of the bidding bank. BTM is measured as the ratio of the book value of common equity to the market value of common equity at year-end prior to the merger completion date, while market capitalization is the market value of common equity at the latest December prior to the deal completion date. Then, according to Bessembinder and Zhang (2013), we 
compute firm-characteristic differences between bidders and their matches for several factors that are likely to affect stock returns: size, book-to-market, beta, illiquidity, return momentum, and idiosyncratic volatility. Lastly, we regress monthly log-return differences between bidders and their matches on these differences in firm characteristics for 24 calendar months after the month the deal is completed. Hence, we assess bidder abnormal stock returns based on the estimated intercept of the following model: ${ }^{19}$

$$
\begin{aligned}
\ln \left(1+R_{b, t}\right)-\ln \left(1+R_{m, t}\right)= & a+\beta_{1} \Delta \text { Size }_{t}+\beta_{2} \Delta B T M_{t}+\beta_{3} \Delta \text { Beta }_{t} \\
& +\beta_{4} \Delta \text { Iliq }_{t}+\beta_{5} \Delta \text { Mom }_{t}+\beta_{6} \Delta \text { IVOL }_{t}+\varepsilon_{t}
\end{aligned}
$$

where $R_{b, t}$ is the monthly return of the bidder firm $b$ on month $t, R_{m, t}$ is the monthly return of the matching firm $m$ on month $t, \Delta$ denotes the normalized difference between bidders and their matches for each month $t$, Size is the market value of equity at the end of the latest June, $B T M$ for July of year $t$ to June of year $t+1$ is the ratio of the book value of common equity at the end of the fiscal year $t-1$, to the market value of common equity at the end of year $t-1$, Beta for July of year $t$ to June of year $t+1$ is estimated using the market model on monthly stock returns over the years $t-5$ to $t-1$, Illiq for July of year $t$ to June of year $t+1$ is defined as the market-adjusted average ratio of daily absolute stock returns to dollar trading volume for July of year $t-1$ to June of year $t,{ }^{20}$ Mom represents the return momentum which is estimated as the cumulative return over months -12 to -2 , and $I V O L$ is the idiosyncratic volatility which is measured as the annualized standard deviation of the residuals estimated from a Fama and French (1993) three factor regression model, using daily returns over month -2 . In each calendar month, we normalize the initial characteristic differences in the scale of -1 to +1 , with 0 corresponding to the difference with the closest value to 0 .

\footnotetext{
${ }^{19}$ We also convert the estimated intercept on a wealth relative (WR) between bidding and matching firms based on the equation $W R=\exp (\hat{a} T)$, where $\hat{a}$ is the estimated intercept and $T$ is the number of months after the month the merger is completed.

${ }^{20}$ As in Amihud (2002), each firm's illiquidity on a period $t$ is divided by the market illiquidity over the same period. Market illiquidity is the average illiquidity of all stocks that have return data for more than 200 days (from July of year $t-1$ to June of year $t$ ). We eliminate illiquidity outliers at the highest and lowest $1 \%$.
} 
Table 12 reports results of the estimated equation (10) for the bidding firms of our postDFA sub-sample. ${ }^{21}$ To be consistent with our short-term analysis, we run regressions of bidder long-run returns for bidders of small, medium-sized, and large mergers, respectively. ${ }^{22}$ Column (1) presents results for small mergers, without controlling for any differences between bidding and matching firms. The estimated intercept is insignificant, suggesting that there are no long-run abnormal returns to bidding firms in small M\&As. In columns (2) and (3), we allow for differences in firm characteristics and their squared terms, respectively. In both cases, the estimated intercept remains insignificant. For medium-sized mergers, the significantly negative coefficient of the estimated intercept in column (4) suggests that bidders' accumulated returns are on average 11\% smaller compared to their size- and BTMmatched firms (wealth relative of 0.89). However, when we add the first and second order terms in the equations, the estimated intercept becomes insignificant. For large deals, we observe a positive and statistically significant intercept when we control for all six differences in firm characteristics. Nevertheless, when we account for the non-linear relation between firm characteristics and abnormal returns, the coefficient of the estimated intercept loses any significance. ${ }^{23}$

\section{$\underline{\text { Insert Table } 12 \text { here }}$}

Overall, the analysis of the bidder long-run stock performance yields interesting conclusions. First, our results contrast the well-stylized fact that bidding firms realize statistically negative long-run abnormal returns after the merger (Loughran and Vijh, 1997;

\footnotetext{
${ }^{21}$ Following Bessembinder and Zhang (2013), along with the pooled OLS regressions, we also implement the Fama and MacBeth (1973) procedure to ensure the robustness of our results. However, to improve the accuracy of such estimates, they require at least 20 firm observations per calendar month. In our sample, this requirement could be applicable only to the small mergers sub-sample. For this reason, we estimate the Fama and MacBeth regression only for small mergers. The results remained unchanged.

${ }^{22}$ From the original sample of 55 small mergers, we exclude the acquisition of State Investors Bancorp, Inc. from First NBC Bank Holding Company, due to the fact that the latter firm went bankrupt a few months after the acquisition, realizing extraordinary monthly returns in the order of $-98.43 \%$.

${ }^{23}$ At this point it should be noted that the buy-and-hold abnormal returns (BHARs) are equivalent with the estimated intercepts of models 1, 4, and 7. BHARs for the small, medium-sized, and large mergers are $-2.67 \%$, $-13.63 \%$, and $4.93 \%$, respectively, and they are only significant for the medium-sized deals.
} 
Betton et al., 2008). In fact, our findings are in line with Bessembinder and Zhang (2013), since when we account for differences in firm characteristics and their squared terms, any significance in long-run abnormal returns disappears. Second, our results are consistent with the market efficiency hypothesis, because any long-term return anomalies are fully explained by differences in characteristics between bidder and matching firms. Therefore, we propose that announcement period abnormal returns should provide an accurate market estimate of the merger-related wealth effects. Therefore, the positive DFA effect on small bank mergers is relatively robust overtime, since it is not followed by a significantly negative market reaction in the longer run.

\subsection{Is there a DFA effect on non-U.S. bank M\&As?}

Up to this point, our empirical evidence suggests that the DFA has altered the way the market participants respond to the announcement of small bank mergers. However, it is likely that the observed pattern in abnormal returns relates to other confounding factors, such as the international economic conditions or the implementation of Basel III. To address this concern, we collect a sample of non-U.S. bank M\&As, and we examine whether the DFA effect is evident outside the United States (where the DFA is not effective).

We retrieve merger data for non-U.S deals from the Thomson ONE database. By applying the same criteria with the U.S. dataset, we obtain a final sample of 195 completed bank mergers between non-U.S. banks. ${ }^{24}$ Equity return data are collected from Datastream and accounting data from Worldscope. Further, we also examine a sub-sample of 94 European bank mergers, since financial markets in Europe are more integrated compared to other nonU.S. countries. In the sub-sample of European bank mergers, we restrict that both bidders and targets are located in the European Union (EU-15), Norway and Switzerland (Vallascas and Hagendorff, 2011).

\footnotetext{
${ }^{24} \mathrm{We}$ eliminate one merger due to the fact that the bidder experienced extraordinary returns at the announcement date. In fact, Vestjysk Bank A/S realized announcement abnormal returns of 55.47\%.
} 
We estimate bidder, target, and combined cumulative abnormal returns over a three-day window centered on the announcement date for all 195 non-U.S. bank mergers. ${ }^{25}$ As in DeLong (2003), bidders realize insignificant returns, while target abnormal returns are positive and statistically significant. Overall, the sampled deals do not create value for the combined entities. This pattern in abnormal returns persists also in the European sub-sample, since bidder and combined CARs are insignificant, and target CARs are positive and significant (Campa and Hernando, 2006; Asimakopoulos and Athanasoglou, 2013; Beltratti and Paladino, 2013).

To evaluate whether abnormal returns in small non-U.S. and/or European mergers are significantly higher after the DFA, we estimate the difference-in-differences model of equation (6). For each dependent variable, we run two separate regressions, one for the whole sample of 195 non-U.S. deals, and one for the sub-sample of 94 European deals. Notably, as we observe in Table 13, the DD estimator is not significant in any regression model. ${ }^{26}$ Hence, we conclude that the DFA effect on announcement period returns is only evident in the U.S. market, a finding which strengthens the interpretation of our results for the U.S. banking industry.

\section{Insert Table 13 here}

\section{Conclusion}

In this paper, we initially examine whether the Dodd-Frank Act has a significant impact in the merger activity of U.S. banks. Increased compliance costs, stringent capital and prudential standards and fear of lost opportunities are likely drivers of bank consolidation. In fact, we

\footnotetext{
${ }^{25}$ Abnormal returns are estimated using the market model. The estimation period consists of 180 trading days and ends 21 trading days before the event date. For the non-U.S. sample, we use the MSCI World index as the benchmark index. For the European sample, we use the STOXX Europe 600 banks as the benchmark index. The results are robust to the use of several other event windows.

${ }^{26}$ It is possible that the insignificant results are driven by a power issue, due to the substantially smaller sample size, compared to the U.S. sample. For this reason, we replicate the DD analysis of Table 4 using a random subsample of 195 deals, drawn from the initial sample of 640 M\&As. Again, the DD estimator is positive and significant in both regressions of bidder and combined CARs.
} 
observe a surge in small bank M\&As after the Act's enactment. Small banks became significantly more acquisitive after the DFA, since getting larger helps these institutions to cover the costs of complying with the new regulations. In contrast, merging activity of medium-sized and large banks is considerably lower after the DFA, than before.

Based on our research question, we investigate whether the DFA has effected changes on the way market participants view U.S. bank M\&As. By comparing deals before and after the Act's passage, we document a positive DFA effect on announcement returns of small deals. At the univariate level, bidder and combined announcement CARs are significantly higher in small bank mergers after the DFA's enactment. At the multivariate level, the results of the difference-in-differences regression models also indicate that small bank mergers create more shareholder value after the DFA, compared to larger deals.

To shed more light in the potential sources of this documented improvement in small deals abnormal returns, we examine the long-run performance of the merging firms of our sample. In support of our arguments, we find that after the DFA, small bank mergers are significantly more profitable and achieve higher savings in the cost of labor compared to larger deals. More importantly, our evidence suggests that the significant reductions in the per-employee cost of labor lead to higher profits, which in turn lead to higher abnormal returns. 


\section{References}

Abadie, A., Imbens, G., 2006. Large sample properties of matching estimators for average treatment effects. Econometrica 74, 235-267.

Aiello, M.J., Tarbert, H.P., 2010. Bank M\&A in the wake of Dodd-Frank. Banking Law Journal 127, 909-923.

Akhigbe, A., Martin, A.D., Whyte, A.M., 2016. Dodd-Frank and risk in the financial services industry. Review of Quantitative Finance and Accounting 47, 395-415.

Alexandridis, G., Antypas, N., Travlos, N.G., 2017. Value creation from M\&As: New evidence. Journal of Corporate Finance 45, 632-650.

Almeida, H., Campello, M., Laranjeira, B., Weisbenner, S., 2012. Corporate debt maturity and the real effects of the 2007 credit crisis. Critical Finance Review 1, 3-58.

Amihud, Y., 2002. Illiquidity and stock returns: Cross-section and time-series effects. Journal of Financial Markets 5, 31-56.

Asimakopoulos, I., Athanasoglou, P.P., 2013. Revisiting the merger and acquisition performance of European banks. International Review of Financial Analysis 29, 237249.

Balasubramnian, B., Cyree, K.B., 2014. Has market discipline on banks improved after the Dodd-Frank Act? Journal of Banking and Finance 41, 155-166.

Barber, B.M., Lyon, J.D., 1997. Detecting long-run abnormal stock returns: The empirical power and specification of test statistics. Journal of Financial Economics 43, 341-372.

Becher, D.A., 2000. The valuation effects of bank mergers. Journal of Corporate Finance 6, 189-214.

Becher, D.A., Campbell, T.L., 2005. Interstate banking deregulation and the changing nature of bank mergers. Journal of Financial Research 28, 1-20.

Beltratti, A., Paladino, G., 2013. Is M\&A different during a crisis? Evidence from the European banking sector. Journal of Banking and Finance 37, 5394-5405.

Bessembinder, H., Zhang, F., 2013. Firm characteristics and long-run stock returns after corporate events. Journal of Financial Economics 109, 83-102.

Betton, S., Eckbo, B.E., Thorburn, K.S., 2008. Corporate takeovers. In: Eckbo, B.E. (Ed.), Handbook of Corporate Finance: Empirical Corporate Finance, Vol. 2. Elsevier, Amsterdam.

Boehmer, E., Masumeci, J., Poulsen, A.B., 1991. Event-study methodology under conditions of event-induced variance. Journal of Financial Economics 30, 253-272.

Brewer, E., Jagtiani, J., 2013. How much did banks pay to become too-big-to-fail and to become systemically important? Journal of Financial Services Research 43, 1-35.

Brown, S.J., Warner, J.B., 1985. Using daily stock returns: The case of event studies. Journal of Financial Economics 14, 3-31.

Campa, J.M., Hernando, I., 2006. M\&As performance in the European financial industry. Journal of Banking and Finance 30, 3367-3392.

Cornett, M.M., De, S., 1991. Common stock returns in corporate takeover bids: Evidence from interstate bank mergers. Journal of Banking and Finance 15, 273-295. 
Cornett, M.M., McNutt, J.J., Tehranian, H., 2006. Performance changes around bank mergers: Revenue enhancements versus cost reductions. Journal of Money Credit and Banking 38, 1013-1050.

Corrado, C.J., 1989. A nonparametric test for abnormal security-price performance in event studies. Journal of Financial Economics 23, 385-395.

Cowan, A.R., Salotti, V., 2015. The resolution of failed bank during the crisis: Acquirer performance and FDIC guarantees, 2008-2013. Journal of Banking and Finance 54, 222-238.

Cumming, D., Dai, N., Johan, S., 2019. Dodd-Franking the hedge funds. Journal of Banking and Finance, forthcoming.

Cyree, K.B., 2016. The effects of regulatory compliance for small banks around crisis-based regulation. Journal of Financial Research 39, 215-245.

Dahl, D., Fuchs, J., Meyer, A., Neely, M., 2018. Compliance costs, economies of scale and compliance performance. Evidence from a survey of community banks. Division of Bank Supervision, Federal Reserve Bank of St. Louis.

Dahya, J., Golubov, A., Petmezas, D., Travlos, N.G., 2019. Governance mandates, outside directors, and acquirer performance. Journal of Corporate Finance, forthcoming.

Dehejia, R.H., Wahba, S., 2002. Propensity score-matching methods for nonexperimental causal studies. Review of Economics and Statistics 84, 151-161.

DeLong, G.L., 2001. Stockholder gains from focusing versus diversifying bank mergers. Journal of Financial Economics 59, 221-252.

DeLong, G.L., 2003. The announcement effects of U.S. versus non-U.S. bank mergers: Do they differ? Journal of Financial Research 26, 487-500.

DeLong, G.L., DeYoung, R., 2007. Learning by observing: Information spillovers in the execution and valuation of commercial bank M\&As. Journal of Finance 62, 181-216.

Depman, J., 2014, KPMG Community Banking Survey.

DeYoung, R., Evanoff, D.D., Molyneux, P., 2009. Mergers and acquisitions of financial institutions: A review of the post-2000 literature. Journal of Financial Services Research 36, 87-110.

Dutta, S., Jog, V., 2009. The long-term performance of acquiring firms: A re-examination of an anomaly. Journal of Banking and Finance 33, 1400-1412.

Fama, E.F., 1998. Market efficiency, long-term returns, and behavioral finance. Journal of Financial Economics 49, 283-306.

Fama, E.F., French, K.R., 1993. Common risk factors in the returns on stocks and bonds. Journal of Financial Economics 33, 3-56.

Fama, E.F., MacBeth, J.D., 1973. Risk, return, and equilibrium: Empirical tests. Journal of Political Economy 81, 607-636.

Feldman, R., Heinecke, K., Schmidt, J., 2013. Quantifying the costs of additional regulation on community banks. Economic Policy Paper 13-3, Federal Reserve Bank of Minneapolis. 
Gao,Y., Liao, S., Wang, X., 2018. Capital markets' assessment of the economic impact of the Dodd-Frank Act on systemically important financial firms. Journal of Banking and Finance 86, 204-223.

Hagendorff, J., Vallascas, F., 2011. CEO pay incentives and risk-taking: Evidence from bank acquisitions. Journal of Corporate Finance 17, 1078-1095.

Hannan, T.H., Wolken, J.D., 1989. Returns to bidders and targets in the acquisition process: Evidence from the banking industry. Journal of Financial Services Research 3, 5-16.

Heckman, J., Ichimura, H., Smith, J., Todd, P., 1998. Characterizing selection bias using experimental data. Econometrica 66, 1017-1098.

Hoskins, S.M., Labonte, M., 2015. An analysis of the regulatory burden on small banks. Working paper, Congressional Research Service.

Houston, J.F., James, C.M., Ryngaert, M.D., 2001. Where do merger gains come from? Bank mergers from the perspective of insiders and outsiders. Journal of Financial Economics 60, 285-331.

Houston, J.F., Ryngaert, M.D., 1994. The overall gains from large bank mergers. Journal of Banking and Finance 18, 1155-1176.

Houston, J.F., Ryngaert, M.D., 1997. Equity issuance and adverse selection: A direct test using conditional stock offers. Journal of Finance 52, 197-219.

Knapp, M., Gart, A., Becher, D.A., 2005. Post-merger performance of bank holding companies, 1987-1998. Financial Review 40, 549-574.

Kuppuswamy, V., Villalonga, B., 2015. Does diversification create value in the presence of external financing constraints? Evidence from the 2007-2009 financial crisis. Management Science 62, 905-923.

Li, K., Prabhala, N.R., 2007. Self-selection models in corporate finance. In: Eckbo, B.E. (Ed.), Handbook of Corporate Finance: Empirical Corporate Finance, Vol. 1. Elsevier, Amsterdam.

Lechner, M., 2011. The estimation of causal effects by difference-in-difference methods. Foundations and Trends in Econometrics 4, 165-224.

Loughran, T., Ritter, J.R., 1995. The new issues puzzle. Journal of Finance 50, 23-51.

Loughran, T., Vijh, A.M., 1997. Do long-term shareholders benefit from corporate acquisitions? Journal of Finance 52, 1765-1790.

Marsh, T.D., 2015. Reforming the regulation of community banks after Dodd-Frank. Indiana Law Journal 90, 179-235.

Masulis, R.W., Wang, C., Xie, F., 2007. Corporate governance and acquirer returns. Journal of Finance 62, 1851-1889.

Moeller, S.B., Schlingemann, F.P., Stulz, R.M., 2004. Firm size and the gains from acquisitions. Journal of Financial Economics 73, 201-228.

Morse, A., 2011. Payday lenders: Heroes or villains? Journal of Financial Economics 102, 28-44.

Peirce, H., Robinson, I., Stratmann, T., 2014. How are small banks faring under Dodd-Frank? Working paper, available at SSRN: http://ssrn.com/abstract=2435206. 
Rau, P.R., Vermaelen, T., 1998. Glamour, value and the post-acquisition performance of acquiring firms. Journal of Financial Economics 49, 223-253.

Roberts, M.R., Whited, T.M., 2013. Endogeneity in empirical corporate finance. In: Constantinides, G.M., Harris, M., Stulz, R.M. (Eds.), Handbook of the Economics of Finance, Vol. 2. Elsevier, Amsterdam.

Skeel, D., 2011. The New Financial Deal: Understanding the Dodd-Frank Act and its (Unintended) Consequences. John Wiley \& Sons, Inc., New Jersey.

Stock, J.H., Yogo, M., 2005. Testing for weak instruments in linear IV regression. In: Andrews D.W.K., Stock J.H. (Eds.), Identification and Inference for Econometric Models, Cambridge University Press, Cambridge.

Travlos, N.G., 1987. Corporate takeover bids, methods of payment, and bidding firms' stock returns. Journal of Finance 42, 943-963.

Trifts, J.W., Scanlon, K.P., 1987. Interstate bank mergers: The early evidence. Journal of Financial Research 10, 305-313.

Tsoutsoura, M., 2015. The effect of succession taxes on family firm investment: Evidence from a natural experiment. Journal of Finance 70, 649-688.

Vallascas, F., Hagendorff, J., 2011. The impact of European bank mergers on bidder default risk. Journal of Banking and Finance 35, 902-915. 
Appendix: Variable definitions

\begin{tabular}{|c|c|}
\hline \multicolumn{2}{|c|}{ Panel A: Deal-Specific Variables } \\
\hline Variables & Definition \\
\hline State & $\begin{array}{l}\text { Dummy variable: } 1 \text { if both bidder and target are headquartered in the same } \\
\text { state, and } 0 \text { otherwise. }\end{array}$ \\
\hline Stock & Dummy variable: 1 if the deal is financed with stock, and 0 otherwise. \\
\hline Combo & $\begin{array}{l}\text { Dummy variable: } 1 \text { if the deal is financed with a combination of cash and } \\
\text { stock, and } 0 \text { otherwise. }\end{array}$ \\
\hline Relative Size & $\begin{array}{l}\text { The ratio of target to bidder total assets at year-end prior to the merger } \\
\text { announcement. }\end{array}$ \\
\hline Small & $\begin{array}{l}\text { Dummy variable: } 1 \text { for mergers with combined firms' assets of less than } \\
\$ 10 \text { billion, and } 0 \text { otherwise. }\end{array}$ \\
\hline Deal Value & Transaction value (in billion $\$$ ). \\
\hline Days to Completion & The difference between the merger announcement and completion date. \\
\hline Bid Premium & $\begin{array}{l}\text { Offer price per target share divided by the target's market price per share } 5 \\
\text { days before the announcement date. }\end{array}$ \\
\hline \multicolumn{2}{|c|}{ Panel B: Firm-Specific Variables } \\
\hline Acquirer's Size & $\begin{array}{l}\text { The natural logarithm of the bidding firm's total assets at year-end prior to } \\
\text { the merger announcement. }\end{array}$ \\
\hline $\begin{array}{l}\text { Bidder (or Target) } \\
\text { ROA }\end{array}$ & $\begin{array}{l}\text { Bidder (or target) firm's return on assets (ROA) at year-end prior to the } \\
\text { merger announcement (Net Income/Total Assets). }\end{array}$ \\
\hline Roadiff & The difference between bidder and target return on assets. \\
\hline $\begin{array}{l}\text { Bidder (or Target) } \\
\text { Employees }\end{array}$ & $\begin{array}{l}\text { Bidder (or target) firm's number of employees (in thousands) at year-end } \\
\text { prior to the merger announcement. }\end{array}$ \\
\hline $\begin{array}{l}\text { Bidder (or Target) } \\
\text { equity-to-assets }\end{array}$ & $\begin{array}{l}\text { Bidder (or target) firm's ratio of common equity at year-end prior to the } \\
\text { merger announcement to total assets at year-end prior to the merger } \\
\text { announcement. }\end{array}$ \\
\hline \multicolumn{2}{|c|}{ Panel C: Performance Variables } \\
\hline $\begin{array}{l}\text { Bidder (or Target) pre- } \\
\text { tax ROA }\end{array}$ & Bidder (or target) firm's ratio of net income before taxes to total assets. \\
\hline $\begin{array}{l}\text { Bidder (or Target) pre- } \\
\text { tax ROE }\end{array}$ & $\begin{array}{l}\text { Bidder (or target) firm's ratio of net income before taxes to common } \\
\text { shareholders' equity. }\end{array}$ \\
\hline Bidder (or Target) Pay & The ratio of the bidder (or target) firm's salaries to number of employees. \\
\hline Bidder (or Target) Sal & The ratio of the bidder (or target) firm's total salaries to total assets. \\
\hline Bidder (or Target) Loan & The ratio of the bidder (or target) firm's loans to number of employees. \\
\hline \multicolumn{2}{|c|}{ Panel D: Long-Run Abnormal Returns } \\
\hline Size & Market capitalization at the end of the latest June. \\
\hline BTM & $\begin{array}{l}\text { BTM for July of year } t \text { to June of year } t+1 \text { is the ratio of the book value of } \\
\text { common equity at the end of the fiscal year } t-1 \text { to the market value of } \\
\text { common equity at the end of year } t-1 \text {. }\end{array}$ \\
\hline Beta & $\begin{array}{l}\text { Beta for July of year } \mathrm{t} \text { to June of year } \mathrm{t}+1 \text { is the market beta estimated using } \\
\text { the market model with monthly stock returns during years } t-5 \text { to } t-1 \text {. }\end{array}$ \\
\hline Illiq & $\begin{array}{l}\text { Illiq for July of year } t \text { to June of year } t+1 \text { is the average ratio of daily stock } \\
\text { returns to dollar trading volume for July of year } t-1 \text { to June of year, relative } \\
\text { to the average market illiquidity over the same period. }\end{array}$ \\
\hline Mom & Cumulative stock returns over months -12 to -2 . \\
\hline IVOL & $\begin{array}{l}\text { The annualized standard deviation of the residuals estimated from a Fama } \\
\text { and French (1993) three factor regression model, using daily returns over } \\
\text { month }-2 \text {. }\end{array}$ \\
\hline
\end{tabular}




\section{Figure 1}

\section{U.S. bank M\&As from 1990 to 2014}

The figure illustrates the annual number of deals of completed U.S. bank mergers announced between 1990 and 2014. The sample consists of mergers between commercial banks and savings institutions with three-digit SIC codes of 602 and 603, respectively, or bank holding companies with a four-digit SIC code of 6712, listed on NYSE, Amex and Nasdaq exchanges. Small, medium-sized, and large mergers represent mergers with combined firms' assets of less than $\$ 10$ billion, between $\$ 10$ billion and $\$ 50$ billion, and greater than $\$ 50$ billion, respectively. Merger data are collected from Thomson ONE database.

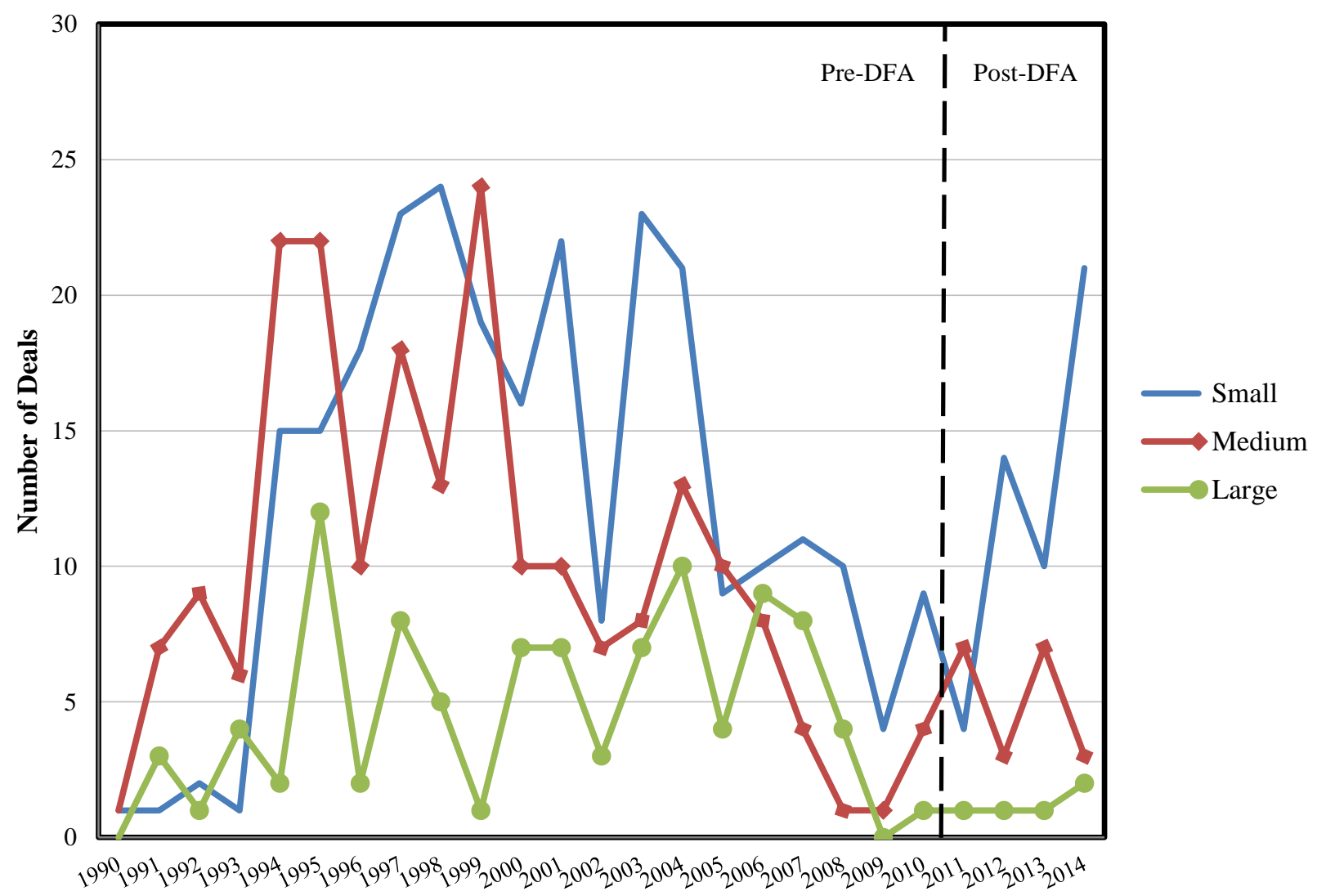




\section{Table 1}

\section{Distribution of merging firm's total assets}

The table illustrates the distribution of the merging firms' total assets for 640 completed bank mergers announced between 1990 and 2014. The sample is divided into three separate asset-size categories: Small, medium-sized, and large banking organizations are those banks with assets of less than $\$ 10$ billion, between $\$ 10$ billion and $\$ 50$ billion, and greater than $\$ 50$ billion, respectively. Panels A and B segment the sample based on whether the merger was announced before or after the enactment of the Dodd-Frank Act (July 21, 2010). For the two separate sub-periods, we report summary statistics for the bidder, target and combined firm's total assets at year-end prior to the merger announcement (in billion \$).

\begin{tabular}{llll}
\hline Panel A: Pre-DFA & Small & Medium & Large \\
\hline Bidders & $n=275$ & $n=203$ & $n=79$ \\
\hline Mean & 3.440 & 25.508 & 178.273 \\
Median & 2.599 & 23.034 & 101.820 \\
Min & 0.097 & 10.094 & 50.856 \\
Max & 9.856 & 49.902 & 1715.746 \\
Std. Dev. & 2.748 & 11.648 & 245.433 \\
\hline Targets & $n=499$ & $n=38$ & $n=20$ \\
\hline Mean & 1.500 & 22.765 & 147.033 \\
Median & 0.762 & 21.397 & 79.382 \\
Min & 0.500 & 10.540 & 51.238 \\
Max & 9.711 & 46.679 & 782.896 \\
Std. Dev. & 1.817 & 10.614 & 168.518 \\
\hline Combined & $n=255$ & $n=205$ & $n=97$ \\
\hline Mean & 3.668 & 25.447 & 195.046 \\
Median & 2.861 & 22.666 & 105.526 \\
Min & 0.157 & 10.033 & 50.064 \\
Max & 9.862 & 49.342 & 1927.476 \\
Std. Dev. & 2.588 & 11.705 & 283.205 \\
\hline Panel B: Post-DFA & Small & Medium & Large \\
\hline Bidders & $n=61$ & $n=16$ & $n=6$ \\
\hline Mean & 4.583 & 14.407 & 103.774 \\
Median & 4.087 & 13.759 & 73.402 \\
Min & 0.616 & 10.074 & 53.667 \\
Max & 9.727 & 25.037 & 183.010 \\
Std. Dev. & 2.759 & 3.998 & 62.001 \\
\hline Targets & $n=79$ & $n=4$ & $n=0$ \\
\hline Mean & 1.557 & 21.705 & N/A \\
Median & 0.941 & 15.183 & N/A \\
Min & 0.198 & 11.097 & N/A \\
Max & 9.463 & 45.356 & N/A \\
Std. Dev. & 1.835 & 16.110 & $n=6$ \\
\hline Combined & $n=55$ & $n=22$ & 117.564 \\
\hline Mean & 4.948 & 16.071 & 101.629 \\
Median & 4.401 & 14.712 & 56.917 \\
Min & 1.196 & 10.228 & 201.483 \\
Max & 27.890 & 63.470 \\
Std. Dev. & 5.179 & \\
& 2.485 & & \\
\hline & & & \\
\hline & & & \\
\hline & & & \\
\hline
\end{tabular}




\section{Table 2}

\section{Summary statistics}

This table summarizes descriptive statistics for a sample of 640 completed bank mergers announced between 1990 and 2014. We report summary statistics for the whole period as well as for the two separate sub-periods (pre-DFA, and post-DFA). Difference represents the differences in mean and median values between the postDFA and the pre-DFA periods. All continuous variables are defined in the Appendix. Panel A displays statistics for firm-specific variables. Panel B provides statistics for deal-specific variables. Method of payment is expressed by the percentages of cash, stock and both cash and stock deals. Geographic diversification is measured by $\%$ same state deals. Target's equity percentages sought and acquired represent the proportion of target's equity the bidder sought and managed to acquire, respectively. Median values are in brackets. Significance for differences in means (medians) is based on the $t$-test (Mann-Whitney test). The symbols *, **, and $* * *$ denote statistical significance at the 0.10, 0.05 and 0.01 levels, respectively, using a 2-tail test.

\begin{tabular}{|c|c|c|c|c|}
\hline & Whole Period & Pre-DFA & Post-DFA & Difference \\
\hline Panel A: Firm-Specific Variables & $(1)$ & $(2)$ & (3) & $(3)-(2)$ \\
\hline Bidder Assets (in billion \$) & $\begin{array}{l}36.497 \\
{[9.220]}\end{array}$ & $\begin{array}{l}36.862 \\
{[10.158]}\end{array}$ & $\begin{array}{l}13.489 \\
{[5.536]}\end{array}$ & $\begin{array}{l}-23.373 * \\
{[-4.622]^{* * *}}\end{array}$ \\
\hline Target Assets (in billion \$) & $\begin{array}{l}7.442 \\
{[0.913]}\end{array}$ & $\begin{array}{l}8.176 \\
{[0.896]}\end{array}$ & $\begin{array}{l}2.515 \\
{[0.985]}\end{array}$ & $\begin{array}{l}-5.661 \\
{[0.089]}\end{array}$ \\
\hline Relative Size & $\begin{array}{l}0.301 \\
{[0.147]}\end{array}$ & $\begin{array}{l}0.294 \\
{[0.136]}\end{array}$ & $\begin{array}{l}0.350 \\
{[0.240]}\end{array}$ & $\begin{array}{l}0.056 \\
{[0.104]^{* * *}}\end{array}$ \\
\hline Bidder ROA & $\begin{array}{l}1.060 \\
{[1.079]}\end{array}$ & $\begin{array}{l}1.113 \\
{[1.136]}\end{array}$ & $\begin{array}{l}0.701 \\
{[0.817]}\end{array}$ & $\begin{array}{l}-0.412 * * * \\
{[-0.319] * * *}\end{array}$ \\
\hline Target ROA & $\begin{array}{l}0.746 \\
{[0.888]}\end{array}$ & $\begin{array}{l}0.817 \\
{[0.938]}\end{array}$ & $\begin{array}{l}0.273 \\
{[0.455]}\end{array}$ & $\begin{array}{l}-0.544 * * * \\
{[-0.483] * * *}\end{array}$ \\
\hline Roadiff & $\begin{array}{l}0.314 \\
{[0.208]}\end{array}$ & $\begin{array}{l}0.296 \\
{[0.202]}\end{array}$ & $\begin{array}{l}0.428 \\
{[0.256]}\end{array}$ & $\begin{array}{l}0.132 \\
{[0.054]}\end{array}$ \\
\hline Bidder equity-to-assets & $\begin{array}{l}0.079 \\
{[0.081]}\end{array}$ & $\begin{array}{l}0.072 \\
{[0.079]}\end{array}$ & $\begin{array}{l}0.126 \\
{[0.116]}\end{array}$ & $\begin{array}{l}0.054 * * * \\
{[0.037]^{* * * *}}\end{array}$ \\
\hline Target equity-to-assets & $\begin{array}{l}0.092 \\
{[0.084]}\end{array}$ & $\begin{array}{l}0.090 \\
{[0.083]}\end{array}$ & $\begin{array}{l}0.107 \\
{[0.100]}\end{array}$ & $\begin{array}{l}0.017 * * * \\
{[0.017]^{* * * *}}\end{array}$ \\
\hline Bidder Employees (in thousands) & $\begin{array}{l}10.009 \\
{[2.975]}\end{array}$ & $\begin{array}{l}11.254 \\
{[4.880]}\end{array}$ & $\begin{array}{l}2.727 \\
{[1.324]}\end{array}$ & $\begin{array}{l}-8.527 * * * \\
{[-3.556] * * *}\end{array}$ \\
\hline Target Employees (in thousands) & $\begin{array}{l}3.020 \\
{[0.292]} \\
\end{array}$ & $\begin{array}{l}3.662 \\
{[0.335]}\end{array}$ & $\begin{array}{l}0.437 \\
{[0.238]} \\
\end{array}$ & $\begin{array}{l}-3.224 * * \\
{[-0.097]^{* * *}}\end{array}$ \\
\hline \multicolumn{5}{|l|}{ Panel B: Deal-Specific Variables } \\
\hline Deal Value (in billion $\$$ ) & $\begin{array}{l}1.193 \\
{[0.164]}\end{array}$ & $\begin{array}{l}1.324 \\
{[0.167]}\end{array}$ & $\begin{array}{l}0.318 \\
{[0.132]}\end{array}$ & $\begin{array}{l}-1.006 * \\
{[-0.035]}\end{array}$ \\
\hline Bid Premium & $\begin{array}{l}1.359 \\
{[1.298]}\end{array}$ & $\begin{array}{l}1.352 \\
{[1.286]}\end{array}$ & $\begin{array}{l}1.400 \\
{[1.342]}\end{array}$ & $\begin{array}{l}0.051 \\
{[0.056]}\end{array}$ \\
\hline Days to Completion & $\begin{array}{l}181.938 \\
{[186.50]}\end{array}$ & $\begin{array}{l}177.874 \\
{[167.00]}\end{array}$ & $\begin{array}{l}209.204 \\
{[188.00]}\end{array}$ & $\begin{array}{l}31.330 * * * \\
{[21.00]^{* * *}}\end{array}$ \\
\hline$\%$ of cash deal & 9.68 & 10.77 & 2.41 & \\
\hline$\%$ of stock deal & 55.47 & 57.27 & 43.37 & \\
\hline$\%$ of both cash and stock deal & 34.85 & 31.96 & 54.22 & \\
\hline$\%$ same state deals & 47.66 & 47.58 & 48.19 & \\
\hline$\%$ Target's equity sought in transaction & 99.72 & 99.68 & 100.00 & \\
\hline$\%$ Target's equity acquired after transaction & 99.71 & 99.68 & 99.93 & \\
\hline
\end{tabular}




\section{Table 3}

\section{CARs around the announcement date}

This table illustrates the bidder, target and combined firms' cumulative abnormal returns (CARs) for a sample of 640 completed bank mergers announced between 1990 and 2014. Panels A to D report bidder, target and combined CARs for the whole period as well as for the two separate sub-periods (pre-DFA, and post-DFA). Difference is the difference in mean CARs between the post-DFA and the pre-DFA periods. Small, mediumsized, and large mergers represent those mergers with combined firms' assets of less than $\$ 10$ billion, between $\$ 10$ billion and $\$ 50$ billion, and greater than $\$ 50$ billion, respectively. Abnormal returns are estimated using the market model for a three-day event window centered on the announcement date $(-1,+1)$. The estimation period consists of 180 trading days and ends 21 trading days before the event date. The parametric test is the standardized cross-sectional test (StdCSect), and the non-parametric test is the Corrado's rank test (Rank Test). Significance for the difference between mean CARs is based on the $t$-test assuming unequal variances. The symbols $* * *$, and $* * *$ denote statistical significance at the $0.10,0.05$ and 0.01 levels, respectively, using a 2tail test.

\begin{tabular}{|c|c|c|c|c|}
\hline & Whole Period & Pre-DFA & Post-DFA & Difference \\
\hline Panel A: All Mergers & $n=640$ & $n=557$ & $n=83$ & \\
\hline Bidder CAR & $-1.66 \%$ & $-1.73 \%$ & $-1.14 \%$ & $0.59 \%$ \\
\hline StdCSect & $(-10.23) * * *$ & $(-10.36)^{* * *}$ & $(-2.01) * *$ & $(t=1.11)$ \\
\hline Rank Test & {$[-7.46]^{* * *}$} & {$[-7.56]^{* * *}$} & {$[-1.62]$} & \\
\hline Target CAR & $20.00 \%$ & $18.78 \%$ & $28.13 \%$ & $9.35 \%$ \\
\hline StdCSect & $(24.41)^{* * *}$ & $(21.56)^{* * *}$ & $(12.78)^{* * *}$ & $(t=3.39) * * *$ \\
\hline Rank Test & {$[10.81]^{* * *}$} & {$[10.40]^{* * *}$} & {$[6.70]^{* * *}$} & \\
\hline Combined CAR & $0.90 \%$ & $0.69 \%$ & $2.32 \%$ & $1.63 \%$ \\
\hline StdCSect & $(4.95) * * *$ & $(3.40)^{* * *}$ & $(4.36) * * *$ & $(t=3.04) * * *$ \\
\hline Rank Test & {$[3.36] * * *$} & {$[1.96]^{*}$} & {$[3.92] * * *$} & \\
\hline Panel B: Small Mergers & $n=310$ & $n=255$ & $n=55$ & \\
\hline Bidder CAR & $-1.51 \%$ & $-1.73 \%$ & $-0.48 \%$ & $1.25 \%$ \\
\hline StdCSect & $(-5.58) * * *$ & $(-6.38)^{* * *}$ & $(-0.40)$ & $(t=1.77)^{*}$ \\
\hline Rank Test & {$[-5.28] * * *$} & {$[-5.68] * * *$} & {$[-0.25]$} & \\
\hline Target CAR & $22.18 \%$ & $20.56 \%$ & $29.67 \%$ & $9.11 \%$ \\
\hline StdCSect & $(15.93)^{* * *}$ & $(13.13)^{* * *}$ & $(10.84)^{* * *}$ & $(t=2.59)^{* * *}$ \\
\hline Rank Test & {$[9.96] * * * *$} & {$[9.54] * * *$} & {$[5.52]^{* * *}$} & \\
\hline Combined CAR & $1.92 \%$ & $1.59 \%$ & $3.44 \%$ & $1.85 \%$ \\
\hline StdCSect & $(7.56) * * *$ & $(5.79) * * *$ & $(5.31)^{* * *}$ & $(t=2.65)^{* * *}$ \\
\hline Rank Test & {$[6.02] * * *$} & {$[4.57]^{* * *}$} & {$[4.55]^{* * *}$} & \\
\hline Panel C: Medium Mergers & $n=227$ & $n=205$ & $n=22$ & \\
\hline Bidder CAR & $-1.83 \%$ & $-1.72 \%$ & $-2.86 \%$ & $-1.14 \%$ \\
\hline StdCSect & $(-8.02)^{* * *}$ & $(-7.42)^{* * *}$ & $(-3.09) * *$ & $(t=1.23)$ \\
\hline Rank Test & {$[-6.16]^{* * *}$} & {$[-5.70]^{* * *}$} & {$[-2.31] * *$} & \\
\hline Target CAR & $18.34 \%$ & $17.31 \%$ & $27.91 \%$ & $10.60 \%$ \\
\hline StdCSect & $(16.67) * * *$ & $(15.24)^{* * *}$ & $(7.77)^{* * *}$ & $(t=2.38)^{* *}$ \\
\hline Rank Test & {$[9.55]^{* * *}$} & {$[9.08]^{* * *}$} & {$[4.36]^{* * *}$} & \\
\hline Combined CAR & $-0.27 \%$ & $-0.26 \%$ & $0.22 \%$ & $0.48 \%$ \\
\hline StdCSect & $(-0.44)$ & $(-0.54)$ & $(0.13)$ & $(t=0.58)$ \\
\hline Rank Test & {$[-0.75]$} & {$[-0.91]$} & {$[0.41]$} & \\
\hline Panel D: Large Mergers & $n=103$ & $n=97$ & $n=6$ & \\
\hline Bidder CAR & $-1.80 \%$ & $-1.77 \%$ & $-0.87 \%$ & $0.90 \%$ \\
\hline StdCSect & $(-4.52) * * *$ & $(-4.41) * * *$ & $(-0.45)$ & $(t=0.49)$ \\
\hline Rank Test & {$[-4.91] * * *$} & {$[-4.64] * * *$} & {$[-0.85]$} & \\
\hline Target CAR & $17.09 \%$ & $17.23 \%$ & $14.78 \%$ & $-2.45 \%$ \\
\hline StdCSect & $(10.42)^{* * *}$ & $(10.48)^{* * *}$ & $(1.58)$ & $(t=0.18)$ \\
\hline Rank Test & {$[5.90]^{* * *}$} & {$[6.13]^{* * *}$} & [0.11] & \\
\hline Combined CAR & $0.31 \%$ & $0.35 \%$ & $-0.25 \%$ & $-0.60 \%$ \\
\hline StdCSect & $(-0.21)$ & $(-0.27)$ & $(0.20)$ & $(t=0.32)$ \\
\hline Rank Test & {$[-1.67]^{*}$} & {$[-1.60]$} & {$[-0.52]$} & \\
\hline
\end{tabular}




\section{Table 4}

\section{Single-difference and difference-in-differences regressions}

This table presents the results of the single-differences and the difference-in-differences regression models. Models 1, 3, and 5 present the results of the single-difference regressions, and models 2, 4, and 6 present the results of the difference-in-differences regressions, for a sample of 640 completed U.S. bank mergers announced between 1990 and 2014. In each regression, the dependent variable is the bidder, target, or combined three-day CARs, centered on the announcement date. All independent variables are defined in the Appendix. All continuous variables are winsorized at $1 \%$ and $99 \%$ level. Heteroskedasticity-robust $t$-statistics are reported in parentheses. The symbols *,**, and *** denote statistical significance at the $0.10,0.05$ and 0.01 levels, respectively, using a 2 -tail test.

\begin{tabular}{|c|c|c|c|c|c|c|}
\hline \multirow[b]{2}{*}{ Variables } & \multicolumn{2}{|l|}{ Bidder } & \multicolumn{2}{|l|}{ Target } & \multicolumn{2}{|l|}{ Combined } \\
\hline & (1) & $(2)$ & (3) & (4) & (5) & (6) \\
\hline Constant & $\begin{array}{l}0.004 \\
(0.31)\end{array}$ & $\begin{array}{l}0.006 \\
(0.55)\end{array}$ & $\begin{array}{l}0.350 * * * \\
(6.07)\end{array}$ & $\begin{array}{l}0.350 * * * \\
(6.07)\end{array}$ & $\begin{array}{l}0.014 \\
(1.16)\end{array}$ & $\begin{array}{l}0.016 \\
(1.36)\end{array}$ \\
\hline DFA & $\begin{array}{l}-0.003 \\
(-0.27)\end{array}$ & $\begin{array}{l}-0.020 \\
(-1.43)\end{array}$ & $\begin{array}{l}0.103 * * \\
(2.18)\end{array}$ & $\begin{array}{l}0.107 * \\
(1.95)\end{array}$ & $\begin{array}{l}0.003 \\
(0.28)\end{array}$ & $\begin{array}{l}-0.012 \\
(-0.98)\end{array}$ \\
\hline Small & $\begin{array}{l}0.003 \\
(0.64)\end{array}$ & $\begin{array}{l}-0.001 \\
(-0.14)\end{array}$ & $\begin{array}{l}0.019 \\
(0.78)\end{array}$ & $\begin{array}{l}0.020 \\
(0.78)\end{array}$ & $\begin{array}{l}0.008 \\
(1.56)\end{array}$ & $\begin{array}{l}0.004 \\
(0.78)\end{array}$ \\
\hline $\mathrm{DFA} \cdot$ Small & & $\begin{array}{l}0.022 * * \\
(2.09)\end{array}$ & & $\begin{array}{l}-0.005 \\
(-0.12)\end{array}$ & & $\begin{array}{l}0.019 * * \\
(2.13)\end{array}$ \\
\hline State & $\begin{array}{l}-0.006 \\
(-1.49)\end{array}$ & $\begin{array}{l}-0.006 \\
(-1.49)\end{array}$ & $\begin{array}{l}0.045^{* * * *} \\
(3.12)\end{array}$ & $\begin{array}{l}0.045 * * * \\
(3.12)\end{array}$ & $\begin{array}{l}-0.000 \\
(-0.13)\end{array}$ & $\begin{array}{l}-0.000 \\
(-0.12)\end{array}$ \\
\hline Stock & $\begin{array}{l}-0.015 * * * \\
(-2.97)\end{array}$ & $\begin{array}{l}-0.015^{* * * *} \\
(-3.02)\end{array}$ & $\begin{array}{l}-0.049 \\
(-1.56)\end{array}$ & $\begin{array}{l}-0.048 \\
(-1.56)\end{array}$ & $\begin{array}{l}-0.015^{* *} \\
(-2.49)\end{array}$ & $\begin{array}{l}-0.015^{* * *} \\
(-2.53)\end{array}$ \\
\hline Combo & $\begin{array}{l}-0.018 * * * \\
(-3.43)\end{array}$ & $\begin{array}{l}-0.018^{* * *} \\
(-3.47)\end{array}$ & $\begin{array}{l}-0.017 \\
(-0.54)\end{array}$ & $\begin{array}{l}-0.017 \\
(-0.53)\end{array}$ & $\begin{array}{l}-0.009 \\
(-1.53)\end{array}$ & $\begin{array}{l}-0.010 \\
(-1.55)\end{array}$ \\
\hline Relative Size & $\begin{array}{l}0.000 \\
(0.02)\end{array}$ & $\begin{array}{l}-0.001 \\
(-0.06)\end{array}$ & $\begin{array}{l}-0.062 * * \\
(-2.07)\end{array}$ & $\begin{array}{l}-0.062 * * \\
(-2.05)\end{array}$ & $\begin{array}{l}0.031 * * * \\
(4.43)\end{array}$ & $\begin{array}{l}0.031 * * * \\
(4.34)\end{array}$ \\
\hline Acquirer's Size & $\begin{array}{l}-0.001 \\
(-0.46)\end{array}$ & $\begin{array}{l}-0.002 \\
(-0.74)\end{array}$ & $\begin{array}{l}-0.002 \\
(-0.24)\end{array}$ & $\begin{array}{l}-0.002 \\
(-0.22)\end{array}$ & $\begin{array}{l}-0.003 \\
(-1.22)\end{array}$ & $\begin{array}{l}-0.003 \\
(-1.47)\end{array}$ \\
\hline Roadiff & $\begin{array}{l}0.000 \\
(1.02)\end{array}$ & $\begin{array}{l}0.000 \\
(1.29)\end{array}$ & $\begin{array}{l}0.000 \\
(0.26)\end{array}$ & $\begin{array}{l}0.000 \\
(0.24)\end{array}$ & $\begin{array}{l}0.000 \\
(0.99)\end{array}$ & $\begin{array}{l}0.000 \\
(1.25)\end{array}$ \\
\hline Target-equity-to-assets & $\begin{array}{l}-0.063 \\
(-1.42)\end{array}$ & $\begin{array}{l}-0.062 \\
(-1.42)\end{array}$ & $\begin{array}{l}-0.912 * * * \\
(-4.41)\end{array}$ & $\begin{array}{l}-0.912 * * * \\
(-4.41)\end{array}$ & $\begin{array}{l}-0.007 \\
(-0.15)\end{array}$ & $\begin{array}{l}-0.007 \\
(-0.14)\end{array}$ \\
\hline Days to Completion & $\begin{array}{l}0.000 \\
(0.37)\end{array}$ & $\begin{array}{l}0.000 \\
(0.50)\end{array}$ & $\begin{array}{l}-0.000 * * \\
(-2.16)\end{array}$ & $\begin{array}{l}-0.000 * * \\
(-2.15)\end{array}$ & $\begin{array}{l}-0.000 \\
(-0.24)\end{array}$ & $\begin{array}{l}-0.000 \\
(-0.10)\end{array}$ \\
\hline $\mathrm{N}$ & 640 & 640 & 640 & 640 & 640 & 640 \\
\hline Adjusted $\mathrm{R}^{2}$ & 0.009 & 0.014 & 0.084 & 0.083 & 0.139 & 0.143 \\
\hline
\end{tabular}




\section{Table 5}

Difference-in-differences estimators for hypothetical treatment periods

This table reports the difference-in-differences estimators of the DD regressions presented in Table 4. All regressions refer to the pre-DFA period. Year denotes the starting year of each hypothetical treatment period. For example, 2006 denotes the period starting from 2006 until the DFA's enactment. Pre and post represent the number of observation in each pre-treatment and post-treatment period, respectively. In all DD models the total number of observations equals 557. The dependent variable in each regression is the bidder, target, or combined three-day CARs centered on the announcement date. Heteroskedasticity-robust $t$-statistics are reported in parentheses.

\begin{tabular}{llllll}
\hline Year & Bidder & Target & Combined & Pre & Post \\
\hline 2006 & -0.011 & 0.018 & -0.009 & 482 & 75 \\
& $(-0.92)$ & $(0.34)$ & $(-0.85)$ & & \\
2005 & -0.010 & 0.031 & -0.006 & 459 & 98 \\
& $(-1.02)$ & $(0.67)$ & $(-0.66)$ & & \\
2004 & -0.007 & 0.011 & -0.010 & 415 & 142 \\
2003 & $(-0.87)$ & $(0.30)$ & $(-1.24)$ & & 180 \\
& -0.002 & -0.008 & -0.004 & 377 & \multirow{2}{*}{$(-0.56)$} \\
2002 & $(-0.33)$ & $(-0.25)$ & -0.003 & 359 & 298 \\
2001 & -0.004 & -0.015 & $(-0.50)$ & & 237 \\
& $(-0.52)$ & $(-0.46)$ & 0.006 & 320 & \\
2000 & -0.001 & -0.019 & $(0.89)$ & & 270 \\
& $(-0.16)$ & $(-0.61)$ & 0.011 & 287 & \\
\hline
\end{tabular}




\section{Table 6}

\section{CARs based on propensity score matching}

This table illustrates CARs based on propensity scores estimated (PSM) from a probit model. In each model, the dependent variable is a dummy variable that equals 1 if the deal is announced after the DFA, and 0 otherwise. Panel A reports the results of the probit model for the whole sample of 640 mergers, and for three separate subsamples of mergers (small, medium-sized, and large). Heteroskedasticity-robust $t$-statistics are reported in parentheses. Panel B reports the average treatment effect on the treated (ATT) for each sample. We report PSM results using the closest-neighbor approach. Standard errors for the ATTs are the heteroskedasticity-consistent standard errors outlined in Abadie and Imbens (2006). The symbols ***, and *** denote statistical significance at the $0.10,0.05$ and 0.01 levels respectively, using a 2-tail test.

\begin{tabular}{|c|c|c|c|c|}
\hline \multirow{2}{*}{$\begin{array}{l}\text { Panel A: Probit estimation results } \\
\text { Post-DFA=1 }\end{array}$} & All & Small & Medium & Large \\
\hline & $(1)$ & $(2)$ & (3) & $(4)$ \\
\hline Constant & $\begin{array}{l}-4.008 * * * \\
(-6.98)\end{array}$ & $\begin{array}{l}-4.584 * * * \\
(-4.96)\end{array}$ & $\begin{array}{l}0.253 \\
(0.20)\end{array}$ & $\begin{array}{l}-8.730 \\
(-0.02)\end{array}$ \\
\hline Small & $\begin{array}{l}0.759 * * * \\
(3.27)\end{array}$ & & & \\
\hline State & $\begin{array}{l}-0.246^{*} \\
(-1.66)\end{array}$ & $\begin{array}{l}-0.311 \\
(-1.60)\end{array}$ & $\begin{array}{l}-0.570 * \\
(-1.88)\end{array}$ & $\begin{array}{l}0.533 \\
(0.96)\end{array}$ \\
\hline Stock & $\begin{array}{l}0.697 * * \\
(1.96)\end{array}$ & $\begin{array}{l}1.051 \\
(1.58)\end{array}$ & $\begin{array}{l}0.086 \\
(0.14)\end{array}$ & $\begin{array}{l}4.956 \\
(0.01)\end{array}$ \\
\hline Combo & $\begin{array}{l}1.067 * * * \\
(3.02)\end{array}$ & $\begin{array}{l}1.487 * * \\
(2.24)\end{array}$ & $\begin{array}{l}0.294 \\
(0.47)\end{array}$ & $\begin{array}{l}5.423 \\
(0.01)\end{array}$ \\
\hline Relative Size & $\begin{array}{l}0.202 \\
(0.98)\end{array}$ & $\begin{array}{l}1.265 * * * \\
(3.81)\end{array}$ & $\begin{array}{l}-0.086 \\
(-0.18)\end{array}$ & $\begin{array}{l}-1.176 \\
(-1.00)\end{array}$ \\
\hline Acquirer's Size & $\begin{array}{l}0.116 \\
(1.51)\end{array}$ & $\begin{array}{l}0.739 * * * \\
(4.90)\end{array}$ & $\begin{array}{l}-1.375 * * * \\
(-3.69)\end{array}$ & $\begin{array}{l}-0.119 \\
(-0.27)\end{array}$ \\
\hline Target-equity-to-assets & $\begin{array}{l}6.084 * * * \\
(3.41)\end{array}$ & $\begin{array}{l}8.764 * * * \\
(3.42)\end{array}$ & $\begin{array}{l}10.858 * * * \\
(2.68)\end{array}$ & $\begin{array}{l}8.764 \\
(1.28)\end{array}$ \\
\hline Days to Completion & $\begin{array}{l}0.005 * * * \\
(4.01)\end{array}$ & $\begin{array}{l}0.003^{*} \\
(1.83)\end{array}$ & $\begin{array}{l}0.007 * * * \\
(2.69)\end{array}$ & $\begin{array}{l}0.009 * * \\
(2.29)\end{array}$ \\
\hline $\begin{array}{l}\mathrm{N} \\
\text { Pseudo } \mathrm{R}^{2}\end{array}$ & $\begin{array}{l}640 \\
0.120\end{array}$ & $\begin{array}{l}310 \\
0.183\end{array}$ & $\begin{array}{l}227 \\
0.267\end{array}$ & $\begin{array}{l}103 \\
0.316\end{array}$ \\
\hline Panel B: ATTs & All & Small & Medium & Large \\
\hline Bidder & & & & \\
\hline $\begin{array}{l}\text { Post-DFA } \\
\text { Pre-DFA matches } \\
\text { Difference }\end{array}$ & $\begin{array}{l}-1.14 \% \\
-1.94 \% \\
0.80 \%\end{array}$ & $\begin{array}{l}-0.48 \% \\
-3.70 \% \\
3.22 \% * * *\end{array}$ & $\begin{array}{l}-2.86 \% \\
-3.08 \% \\
0.22 \%\end{array}$ & $\begin{array}{l}-0.87 \% \\
-3.76 \% \\
2.89 \% \\
\end{array}$ \\
\hline Target & & & & \\
\hline $\begin{array}{l}\text { Post-DFA } \\
\text { Pre-DFA matches } \\
\text { Difference }\end{array}$ & $\begin{array}{l}28.13 \% \\
17.17 \% \\
10.96 \% \text { *** }\end{array}$ & $\begin{array}{l}29.67 \% \\
14.15 \% \\
15.52 \% * * * \\
\end{array}$ & $\begin{array}{l}27.91 \% \\
9.84 \% \\
18.07 \% \text { *** } \\
\end{array}$ & $\begin{array}{l}14.78 \% \\
31.67 \% \\
-16.89 \%\end{array}$ \\
\hline Combined & & & & \\
\hline $\begin{array}{l}\text { Post-DFA } \\
\text { Pre-DFA matches } \\
\text { Difference }\end{array}$ & $\begin{array}{l}2.32 \% \\
1.12 \% \\
1.20 \% \\
\end{array}$ & $\begin{array}{l}3.44 \% \\
-0.29 \% \\
3.75 \% * * * \\
\end{array}$ & $\begin{array}{l}0.22 \% \\
-0.47 \% \\
0.69 \% \\
\end{array}$ & $\begin{array}{l}-0.25 \% \\
-0.58 \% \\
0.33 \%\end{array}$ \\
\hline
\end{tabular}




\section{Table 7}

Single-difference and difference-in-differences regressions for propensity-matched deals

This table summarizes the single-differences and the difference-in-differences regression results using propensity-matched observations. Models 1, 3, and 5 present the results of the single-difference regressions, and models 2, 4, and 6 present the results of the difference-in-differences regressions. Observations of our treatment and control groups for the post-DFA period are matched with their pre-DFA counterparts. In each regression, the dependent variable is the bidder, target, or combined three-day CARs, centered on the announcement date. Control variables are the same with Table 4. All independent variables are defined in the Appendix. All continuous variables are winsorized at $1 \%$ and $99 \%$ level. Heteroskedasticity-robust $t$-statistics are reported in parentheses. The symbols $* *$, and $* * *$ denote statistical significance at the 0.05 and 0.01 levels, respectively, using a 2-tail test.

\begin{tabular}{|c|c|c|c|c|c|c|}
\hline \multirow[b]{2}{*}{ Variables } & \multicolumn{2}{|l|}{ Bidder } & \multicolumn{2}{|l|}{ Target } & \multicolumn{2}{|c|}{ Combined } \\
\hline & (1) & (2) & (3) & (4) & (5) & (6) \\
\hline Constant & $\begin{array}{l}0.007 \\
(0.29)\end{array}$ & $\begin{array}{l}0.014 \\
(0.60)\end{array}$ & $\begin{array}{l}0.313^{* *} \\
(2.50)\end{array}$ & $\begin{array}{l}0.324 * * \\
(2.61)\end{array}$ & $\begin{array}{l}0.012 \\
(0.58)\end{array}$ & $\begin{array}{l}0.019 \\
(0.85)\end{array}$ \\
\hline DFA & $\begin{array}{l}0.013^{*} \\
(1.77)\end{array}$ & $\begin{array}{l}-0.010 \\
(-1.07)\end{array}$ & $\begin{array}{l}0.099^{* * * * *} \\
(3.11)\end{array}$ & $\begin{array}{l}0.064 \\
(1.20)\end{array}$ & $\begin{array}{l}0.018 * * \\
(2.58)\end{array}$ & $\begin{array}{l}-0.004 \\
(-0.42)\end{array}$ \\
\hline Small & $\begin{array}{l}0.006 \\
(0.65)\end{array}$ & $\begin{array}{l}-0.012 \\
(-1.05)\end{array}$ & $\begin{array}{l}-0.015 \\
(-0.32)\end{array}$ & $\begin{array}{l}-0.044 \\
(-0.75)\end{array}$ & $\begin{array}{l}0.001 \\
(0.14)\end{array}$ & $\begin{array}{l}-0.016 \\
(-1.27)\end{array}$ \\
\hline DFA·Small & & $\begin{array}{l}0.034 * * \\
(2.54)\end{array}$ & & $\begin{array}{l}0.052 \\
(0.82)\end{array}$ & & $\begin{array}{l}0.032 \text { ** } \\
(2.56)\end{array}$ \\
\hline Control Variables & Yes & Yes & Yes & Yes & Yes & Yes \\
\hline $\begin{array}{l}\mathrm{N} \\
\text { Adjusted } \mathrm{R}^{2}\end{array}$ & $\begin{array}{l}151 \\
0.000\end{array}$ & $\begin{array}{l}151 \\
0.016\end{array}$ & $\begin{array}{l}151 \\
0.139\end{array}$ & $\begin{array}{l}151 \\
0.136\end{array}$ & $\begin{array}{l}151 \\
0.150\end{array}$ & $\begin{array}{l}151 \\
0.173\end{array}$ \\
\hline
\end{tabular}




\section{Table 8}

Changes in merger performance around M\&As

This table summarizes merger-related differences in financial performance and compliance costs for a sample of completed bank mergers announced between 1990 and 2014. Panel A reports changes in the financial performance of the merging banks and Panel B reports changes in several compliance costs indicators. $\Delta$ denotes the difference between the post-merger industry-adjusted performance of the actual combined bank and the pre-merger industry-adjusted performance of a hypothetical combination of the bidder and target banks. Pre-merger refers to the year-end prior to the merger announcement. Post-merger refers to two years after the pre-merger year. Column (5) is the difference between column (2) and columns (3+4), and represents a difference-in-differences (DD) estimate. Column (6) represents the difference-in-difference-in-differences (DDD) estimate and is the difference between the DD estimate of the post-DFA period and the DD estimate of the pre-DFA period (as presented in column 5). All variables are defined in the Appendix. Significance for the differences is based on the $t$-test assuming unequal variances. The symbols $*, * *$, and $* * *$ denote statistical significance at the $0.10,0.05$ and 0.01 levels, respectively, using a 2 -tail test.

\begin{tabular}{|c|c|c|c|c|c|c|}
\hline Panel A: Changes in financial performance & All & Small & Medium & Large & $\mathrm{DD}$ & DDD \\
\hline$\triangle P r e$-tax $R O A$ & $(1)$ & $(2)$ & $(3)$ & $(4)$ & $(5)$ & $(6)$ \\
\hline Pre-DFA & $-0.0009 * *$ & $-0.0013 * * *$ & 0.0001 & -0.0014 & -0.0009 & $0.0037 * * *$ \\
\hline Post-DFA & -0.0006 & 0.0003 & $-0.0030 * * *$ & -0.0005 & $0.0028 * *$ & \\
\hline (Post-DFA)-(Pre-DFA) & 0.0003 & $0.0016^{*}$ & $-0.0031 * * *$ & 0.0009 & & \\
\hline \multicolumn{7}{|l|}{$\triangle$ Pre-tax ROE } \\
\hline Pre-DFA & $-0.0348 * * *$ & $-0.0374 * * *$ & $-0.0330 * * *$ & $-0.0317 * *$ & -0.0049 & $0.0705 * * *$ \\
\hline Post-DFA & 0.0151 & $0.0378 * * *$ & $-0.0335 * * *$ & -0.0070 & $0.0656^{* * *}$ & \\
\hline (Post-DFA)-(Pre-DFA) & $0.0499 * * *$ & $0.0752 * * *$ & -0.0005 & 0.0247 & & \\
\hline Panel B: Changes in compliance costs & All & Small & Medium & Large & $\mathrm{DD}$ & DDD \\
\hline$\Delta P a y$ & $(1)$ & $(2)$ & $(3)$ & $(4)$ & $(5)$ & $(6)$ \\
\hline Pre-DFA & -0.0052 & $0.0041 * * *$ & -0.0083 & $-0.0157 *$ & $0.0161 * * *$ & $-0.0149 * *$ \\
\hline Post-DFA & $-0.0033 * * *$ & $-0.0029 * * *$ & $-0.0055^{* * *}$ & 0.0009 & 0.0012 & \\
\hline (Post-DFA)-(Pre-DFA) & 0.0019 & $-0.0070 * * *$ & 0.0028 & $0.0166^{*}$ & & \\
\hline \multicolumn{7}{|l|}{$\Delta$ Sal } \\
\hline Pre-DFA & 0.0000 & 0.0002 & -0.0002 & -0.0002 & 0.0004 & 0.0001 \\
\hline Post-DFA & $-0.0009 * * *$ & $-0.0007 * *$ & $-0.0017 * * *$ & 0.0007 & 0.0005 & \\
\hline (Post-DFA)-(Pre-DFA) & $-0.0009 * *$ & $-0.0009 *$ & $-0.0015 * *$ & 0.0005 & & \\
\hline \multicolumn{7}{|l|}{$\Delta$ Loan } \\
\hline Pre-DFA & -0.2697 & 0.1827 & -0.1376 & $-1.0650 *$ & $0.7786^{* *}$ & -0.7373 \\
\hline Post-DFA & -0.0912 & -0.0770 & 0.1313 & -1.0336 & -0.0413 & \\
\hline (Post-DFA)-(Pre-DFA) & 0.1785 & -0.2597 & 0.2689 & -0.0314 & & \\
\hline
\end{tabular}




\section{Table 9}

\section{Difference-in-difference-in-differences regressions and propensity score matching}

This table reports results of the difference-in-difference-in-differences (DDD) regressions and the propensity score matching (PSM) analysis. Panel A reports the DDD estimators. In each column, the dependent variable is different ( $\triangle$ Pre-tax ROA, $\triangle$ Pre-tax ROE, $\triangle$ Pay, $\triangle$ Sal, $\triangle$ Loan). $\triangle$ denotes the difference between the post-merger industry-adjusted performance of the actual combined bank and the pre-merger industry-adjusted performance of a hypothetical combination of the bidder and target banks. Pre-merger refers to the year-end prior to the merger announcement. Post-merger refers to two years after the pre-merger year. Control variables are the same with Table 6 with the addition of Bid Premium. All variables are defined in the Appendix. All continuous variables are winsorized at $1 \%$ and $99 \%$ level. Heteroskedasticity-robust $t$-statistics are reported in parentheses. Panel B reports the average treatment effect on the treated (ATT) for each sample. We report PSM results using the closest-neighbor approach. Standard errors for the ATTs are the heteroskedasticity-consistent standard errors outlined in Abadie and Imbens (2006). Panel C repeats the DDD analysis of Panel A, using PSM-matched deals as the pre-DFA sample. The symbols *,**, and *** denote statistical significance at the $0.10,0.05$ and 0.01 levels, respectively, using a 2-tail test.

\begin{tabular}{|c|c|c|c|c|c|}
\hline \multirow[b]{2}{*}{ Panel A: DDD } & \multicolumn{2}{|l|}{ Profitability } & \multicolumn{3}{|c|}{ Compliance Costs } \\
\hline & $\Delta$ Pre-tax ROA & $\Delta$ Pre-tax ROE & $\Delta$ Pay & $\Delta$ Sal & $\Delta$ Loan \\
\hline Variables & $(1)$ & $(2)$ & (3) & $(4)$ & $(5)$ \\
\hline Constant & $\begin{array}{l}0.004 \\
(1.27)\end{array}$ & $\begin{array}{l}0.054 \\
(1.07)\end{array}$ & $\begin{array}{l}-0.036 \\
(-1.08)\end{array}$ & $\begin{array}{l}0.001 \\
(0.73)\end{array}$ & $\begin{array}{l}1.238 \\
(0.74)\end{array}$ \\
\hline DFA & $\begin{array}{l}-0.002 \\
(-1.64)\end{array}$ & $\begin{array}{l}0.005 \\
(0.35)\end{array}$ & $\begin{array}{l}0.010 \\
(1.43)\end{array}$ & $\begin{array}{l}-0.001 * * \\
(-2.06)\end{array}$ & $\begin{array}{l}0.512 \\
(1.46)\end{array}$ \\
\hline Small & $\begin{array}{l}-0.002 * * \\
(-2.01)\end{array}$ & $\begin{array}{l}-0.025 \\
(-1.47)\end{array}$ & $\begin{array}{l}0.024 * * \\
(2.34)\end{array}$ & $\begin{array}{l}0.000 \\
(0.96)\end{array}$ & $\begin{array}{l}-0.527 \\
(-0.90)\end{array}$ \\
\hline DFA·Small & $\begin{array}{l}0.005 * * * \\
(3.59)\end{array}$ & $\begin{array}{l}0.081 * * * \\
(3.62)\end{array}$ & $\begin{array}{l}-0.017 * * \\
(-2.17)\end{array}$ & $\begin{array}{l}0.001 \\
(1.28)\end{array}$ & $\begin{array}{l}-0.247 \\
(-0.63)\end{array}$ \\
\hline Control Variables & Yes & Yes & Yes & Yes & Yes \\
\hline $\begin{array}{l}\mathrm{N} \\
\text { Adjusted } \mathrm{R}^{2}\end{array}$ & $\begin{array}{l}539 \\
0.051\end{array}$ & $\begin{array}{l}539 \\
0.042\end{array}$ & $\begin{array}{l}353 \\
0.024\end{array}$ & $\begin{array}{l}539 \\
0.045\end{array}$ & $\begin{array}{l}353 \\
0.045\end{array}$ \\
\hline Panel B: ATTs & $\Delta$ Pre-tax ROA & $\Delta$ Pre-tax ROE & $\Delta$ Pay & $\Delta$ Sal & $\Delta$ Loan \\
\hline Small mergers & & & & & \\
\hline $\begin{array}{l}\text { Post-DFA } \\
\text { Pre-DFA matches } \\
\text { Difference }\end{array}$ & $\begin{array}{l}0.0003 \\
-0.0024 \\
0.0027^{* *} \\
\end{array}$ & $\begin{array}{l}0.0378 \\
-0.0800 \\
0.1178 * * *\end{array}$ & $\begin{array}{l}-0.0029 \\
0.0037 \\
-0.0066 * *\end{array}$ & $\begin{array}{l}-0.0007 \\
0.0013 \\
-0.0020 * * \\
\end{array}$ & $\begin{array}{l}-0.0770 \\
0.0788 \\
-0.1558\end{array}$ \\
\hline Medium-sized mergers & & & & & \\
\hline $\begin{array}{l}\text { Post-DFA } \\
\text { Pre-DFA matches } \\
\text { Difference }\end{array}$ & $\begin{array}{l}-0.0030 \\
-0.0027 \\
-0.0003 \\
\end{array}$ & $\begin{array}{l}-0.0335 \\
-0.0762 \\
0.0427 \\
\end{array}$ & $\begin{array}{l}-0.0055 \\
-0.0028 \\
-0.0027 \\
\end{array}$ & $\begin{array}{l}-0.0017 \\
0.0002 \\
-0.0019 * * *\end{array}$ & $\begin{array}{l}0.1313 \\
0.0590 \\
0.0723 \\
\end{array}$ \\
\hline Large mergers & & & & & \\
\hline $\begin{array}{l}\text { Post-DFA } \\
\text { Pre-DFA matches } \\
\text { Difference }\end{array}$ & $\begin{array}{l}-0.0005 \\
-0.0182 \\
0.0177\end{array}$ & $\begin{array}{l}-0.0070 \\
-0.2607 \\
0.2537\end{array}$ & $\begin{array}{l}0.0009 \\
-0.0108 \\
0.0117 \\
\end{array}$ & $\begin{array}{l}0.0007 \\
0.0007 \\
0.0000\end{array}$ & $\begin{array}{l}-1.0336 \\
-0.6527 \\
-0.3809\end{array}$ \\
\hline Panel C: Matched-DDD & $\Delta$ Pre-tax ROA & $\Delta$ Pre-tax ROE & $\Delta$ Pay & $\Delta$ Sal & $\Delta$ Loan \\
\hline Variables & $(1)$ & (2) & $(3)$ & $(4)$ & $(5)$ \\
\hline Constant & $\begin{array}{l}0.005 \\
(1.22)\end{array}$ & $\begin{array}{l}-0.041 \\
(-0.48)\end{array}$ & $\begin{array}{l}0.066^{*} \\
(1.76)\end{array}$ & $\begin{array}{l}0.000 \\
(0.34)\end{array}$ & $\begin{array}{l}0.002 \\
(1.52)\end{array}$ \\
\hline DFA & $\begin{array}{l}-0.004 * * * \\
(-2.67)\end{array}$ & $\begin{array}{l}-0.027 \\
(-1.39)\end{array}$ & $\begin{array}{l}0.027 \\
(1.61)\end{array}$ & $\begin{array}{l}-0.001 * \\
(-1.66)\end{array}$ & $\begin{array}{l}0.001 \\
(1.41)\end{array}$ \\
\hline Small & $\begin{array}{l}-0.005 * * \\
(-2.29)\end{array}$ & $\begin{array}{l}-0.074 * * \\
(-2.12)\end{array}$ & $\begin{array}{l}0.020 \\
(1.52)\end{array}$ & $\begin{array}{l}-0.001 \\
(-1.02)\end{array}$ & $\begin{array}{l}-0.000 \\
(-0.23)\end{array}$ \\
\hline DFA·Small & $\begin{array}{l}0.009 * * * \\
(4.29)\end{array}$ & $\begin{array}{l}0.152 * * * \\
(4.47)\end{array}$ & $\begin{array}{l}-0.027 * \\
(-1.89)\end{array}$ & $\begin{array}{l}0.001 \\
(1.31)\end{array}$ & $\begin{array}{l}-0.001 \\
(-0.78)\end{array}$ \\
\hline Control Variables & Yes & Yes & Yes & Yes & Yes \\
\hline $\begin{array}{l}\mathrm{N} \\
\text { Adjusted } \mathrm{R}^{2}\end{array}$ & $\begin{array}{l}135 \\
0.129\end{array}$ & $\begin{array}{l}135 \\
0.207\end{array}$ & $\begin{array}{l}135 \\
0.382\end{array}$ & $\begin{array}{l}135 \\
0.009\end{array}$ & $\begin{array}{l}135 \\
0.313\end{array}$ \\
\hline
\end{tabular}




\section{Table 10}

\section{Cross-sectional regressions of changes in profitability}

This table summarizes regression results for changes in post-merger financial performance for a sample of completed bank mergers announced between 1990 and 2014. The dependent variable in the first (last) three columns is the pre-tax ROA (pre-tax ROE). $\triangle$ denotes the difference between the post-merger industry-adjusted performance of the actual combined bank and the pre-merger industry-adjusted performance of a hypothetical combination of the bidder and target banks. Pre-merger refers to the year-end prior to the merger announcement. Post-merger refers to two years after the pre-merger year. The definition of $\Delta C o m p l$ changes across columns ( $\triangle P a y, \triangle S a l$, or $\triangle$ Loan). Control variables are the same with Table 9. All variables are defined in the Appendix. All continuous variables are winsorized at $1 \%$ and $99 \%$ level. Heteroskedasticity-robust $t$-statistics are reported in parentheses. The symbols *,**, and *** denote statistical significance at the $0.10,0.05$ and 0.01 levels, respectively, using a 2 -tail test.

\begin{tabular}{|c|c|c|c|c|c|c|}
\hline \multirow[b]{3}{*}{ Variables } & \multicolumn{3}{|c|}{$\Delta$ Pre-tax ROA } & \multicolumn{3}{|c|}{$\Delta$ Pre-tax ROE } \\
\hline & $\Delta$ Pay & $\Delta \mathrm{Sal}$ & $\Delta$ Loan & $\Delta$ Pay & $\Delta \mathrm{Sal}$ & $\Delta$ Loan \\
\hline & (1) & (2) & (3) & (4) & (5) & (6) \\
\hline \multirow[t]{2}{*}{ Constant } & 0.003 & 0.002 & 0.004 & 0.008 & 0.030 & 0.024 \\
\hline & $(0.73)$ & $(0.69)$ & $(0.87)$ & $(0.11)$ & $(0.62)$ & $(0.32)$ \\
\hline \multirow[t]{2}{*}{ DFA } & -0.000 & -0.001 & -0.002 & $0.032 *$ & 0.005 & 0.017 \\
\hline & $(-0.13)$ & $(-1.01)$ & $(-1.16)$ & $(1.89)$ & $(0.27)$ & $(0.93)$ \\
\hline \multirow[t]{2}{*}{ Small } & -0.001 & $-0.002 *$ & -0.001 & -0.014 & -0.026 & -0.014 \\
\hline & $(-0.74)$ & $(-1.86)$ & $(-0.82)$ & $(-0.53)$ & $(-1.38)$ & $(-0.54)$ \\
\hline \multirow[t]{2}{*}{$\Delta$ Compl } & 0.004 & $0.818 * * *$ & -0.000 & -0.037 & 3.723 & -0.001 \\
\hline & $(0.71)$ & $(2.61)$ & $(-0.42)$ & $(-0.41)$ & $(0.69)$ & $(-0.35)$ \\
\hline \multirow[t]{2}{*}{ DFA·Small } & $0.004 * *$ & $0.005 * * *$ & $0.005 * * *$ & $0.072 * *$ & $0.081 * * *$ & $0.089 * * *$ \\
\hline & $(2.31)$ & $(3.03)$ & $(3.14)$ & $(2.48)$ & $(3.30)$ & $(3.19)$ \\
\hline \multirow[t]{2}{*}{$\mathrm{DFA} \cdot \Delta$ Compl } & $0.334 * * *$ & -0.263 & $-0.001 * *$ & $3.918 * * *$ & -2.234 & -0.006 \\
\hline & $(3.62)$ & $(-0.51)$ & $(-2.19)$ & $(4.99)$ & $(-0.33)$ & $(-0.68)$ \\
\hline \multirow[t]{2}{*}{ Small $\cdot \Delta$ Compl } & $-0.027 * *$ & $-0.581 *$ & $-0.000 * *$ & 0.152 & -0.551 & 0.001 \\
\hline & $(-2.49)$ & $(-1.77)$ & $(-2.33)$ & $(1.09)$ & $(-0.10)$ & $(0.35)$ \\
\hline \multirow[t]{2}{*}{ DFA $\cdot$ Small $\cdot \Delta$ Compl } & $-0.289 * *$ & 0.363 & 0.002 & $-3.533 * *$ & -6.944 & 0.044 \\
\hline & $(-2.36)$ & $(0.57)$ & $(0.99)$ & $(-1.99)$ & $(-0.78)$ & $(1.41)$ \\
\hline Control Variables & Yes & Yes & Yes & Yes & Yes & Yes \\
\hline $\mathrm{N}$ & 353 & 539 & 353 & 353 & 539 & 353 \\
\hline Adjusted $\mathrm{R}^{2}$ & 0.098 & 0.121 & 0.092 & 0.052 & 0.054 & 0.050 \\
\hline
\end{tabular}




\section{Table 11}

\section{Financial performance and abnormal returns in small bank M\&As}

This table reports results from two-stage instrumental variable regressions for a sample of small bank M\&As announced from 1990 to 2014. In the first stage regressions, the dependent variable is either the $\triangle p r e$-tax ROA (model 1) or the Apre-tax ROE (model 4). The DFA indicator is used as the instrument for the first-stage regressions. In the second-stage regressions, the dependent variable is either the bidder CARs (models 2 and 5) or the combined CARs (models 3 and 6). Apre-tax ROA and $\triangle p r e$-tax ROE refer to the predicted values from the first-stage regressions. $\Delta$ denotes the difference between the post-merger industry-adjusted performance of the actual combined bank and the pre-merger industry-adjusted performance of a hypothetical combination of the bidder and target banks. Pre-merger refers to the year-end prior to the merger announcement. Post-merger refers to two years after the pre-merger year. Control variables are the same with Table 9. All variables are defined in the Appendix. All continuous variables are winsorized at $1 \%$ and $99 \%$ level. Heteroskedasticity-robust $t$ statistics are reported in parentheses. The symbols $* *$, and $* * *$ denote statistical significance at the 0.05 and 0.01 levels, respectively, using a 2-tail test.

\begin{tabular}{|c|c|c|c|c|c|c|}
\hline Variables & $\begin{array}{l}1^{\text {st }} \text { stage } \\
\Delta \text { Pre-tax } \\
\text { ROA } \\
(1)\end{array}$ & $\begin{array}{l}2^{\text {nd }} \text { stage } \\
\text { Bidder } \\
\text { CAR } \\
(2) \\
\end{array}$ & $\begin{array}{l}2^{\text {nd }} \text { stage } \\
\text { Combined } \\
\text { CAR } \\
(3)\end{array}$ & $\begin{array}{l}1^{\text {st }} \text { stage } \\
\Delta \text { Pre-tax } \\
\text { ROE } \\
(4)\end{array}$ & $\begin{array}{l}2^{\text {nd }} \text { stage } \\
\text { Bidder } \\
\text { CAR } \\
(5)\end{array}$ & $\begin{array}{l}2^{\text {nd }} \text { stage } \\
\text { Combined } \\
\text { CAR } \\
(6)\end{array}$ \\
\hline Constant & $\begin{array}{l}0.004 \\
(1.24)\end{array}$ & $\begin{array}{l}0.043 \\
(1.64)\end{array}$ & $\begin{array}{l}-0.027 \\
(-0.98)\end{array}$ & $\begin{array}{l}0.083 \\
(1.44)\end{array}$ & $\begin{array}{l}0.049 * * \\
(2.49)\end{array}$ & $\begin{array}{l}-0.021 \\
(-0.87)\end{array}$ \\
\hline DFA & $\begin{array}{l}0.003 * * * \\
(3.55)\end{array}$ & & & $\begin{array}{l}0.101 * * * \\
(5.06)\end{array}$ & & \\
\hline$\Delta$ Pre-tax ROA & & $\begin{array}{l}6.307 * * \\
(2.09)\end{array}$ & $\begin{array}{l}5.698 * * \\
(2.00)\end{array}$ & & & \\
\hline$\Delta$ Pre-tax ROE & & & & & $\begin{array}{l}0.202 * * \\
(2.27)\end{array}$ & $\begin{array}{l}0.183 * * \\
(2.11)\end{array}$ \\
\hline Control Variables & Yes & Yes & Yes & Yes & Yes & Yes \\
\hline Craig-Donald F-statistic & 9.59 & & & 26.71 & & \\
\hline Kleibergen-Paap F-statistic & 13.97 & & & 25.46 & & \\
\hline $\mathrm{N}$ & 264 & 264 & 264 & 264 & 264 & 264 \\
\hline Adjusted $\mathrm{R}^{2}$ & 0.079 & 0.119 & 0.116 & 0.097 & 0.119 & 0.116 \\
\hline
\end{tabular}


Table 12

Long-term abnormal stock returns of bidders in bank M\&As

This table summarizes the OLS regression results for the monthly differences in log returns between bidders and their size- and book-to-market matched firms, for 24 months after the merger completion. All independent variables are normalized on a -1 to +1 range and are defined in the Appendix. Robust $t$-statistics are reported in the parentheses. The symbols $* * *$, and $* * *$ denote statistical significance at the $0.10,0.05$ and 0.01 levels, respectively, using a 2 -tail test.

\begin{tabular}{|c|c|c|c|c|c|c|c|c|c|}
\hline \multirow[b]{2}{*}{ Variables } & \multicolumn{3}{|l|}{ Small } & \multicolumn{3}{|l|}{ Medium } & \multicolumn{3}{|l|}{ Large } \\
\hline & $(1)$ & $(2)$ & (3) & (4) & $(5)$ & $(6)$ & $(7)$ & $(8)$ & $(9)$ \\
\hline Constant & $\begin{array}{l}-0.0010 \\
(-0.53)\end{array}$ & $\begin{array}{l}0.0004 \\
(0.21)\end{array}$ & $\begin{array}{l}-0.0102 \\
(-1.47)\end{array}$ & $\begin{array}{l}-0.0049 * * \\
(-2.65)\end{array}$ & $\begin{array}{l}-0.0031 \\
(-1.18)\end{array}$ & $\begin{array}{l}-0.0041 \\
(-1.15)\end{array}$ & $\begin{array}{l}0.0017 \\
(1.24)\end{array}$ & $\begin{array}{l}0.0142 * * \\
(4.44)\end{array}$ & $\begin{array}{l}0.0042 \\
(1.42)\end{array}$ \\
\hline$\Delta$ Size & & $\begin{array}{l}-0.0029 \\
(-0.89)\end{array}$ & $\begin{array}{l}-0.0022 \\
(-0.68)\end{array}$ & & $\begin{array}{l}-0.0022 \\
(-0.64)\end{array}$ & $\begin{array}{l}-0.0039 \\
(-1.37)\end{array}$ & & $\begin{array}{l}-0.0018 \\
(-0.10)\end{array}$ & $\begin{array}{l}0.0242 \\
(1.33)\end{array}$ \\
\hline$\Delta \operatorname{Size}^{2}$ & & & $\begin{array}{l}0.0023 \\
(0.46)\end{array}$ & & & $\begin{array}{l}-0.0015 \\
(-0.33)\end{array}$ & & & $\begin{array}{l}-0.0060 \\
(-0.29)\end{array}$ \\
\hline$\triangle \mathrm{BTM}$ & & $\begin{array}{l}-0.0036 \\
(-1.40)\end{array}$ & $\begin{array}{l}-0.0037 \\
(-1.45)\end{array}$ & & $\begin{array}{l}-0.0004 \\
(-0.10)\end{array}$ & $\begin{array}{l}0.0000 \\
(0.01)\end{array}$ & & $\begin{array}{l}0.0095 \\
(0.70)\end{array}$ & $\begin{array}{l}-0.0972 \\
(-2.79)\end{array}$ \\
\hline$\Delta \mathrm{BTM}^{2}$ & & & $\begin{array}{l}0.0062 \\
(1.62)\end{array}$ & & & $\begin{array}{l}-0.0052 \\
(-0.94)\end{array}$ & & & $\begin{array}{l}0.1032 \\
(2.27)\end{array}$ \\
\hline$\Delta$ Beta & & $\begin{array}{l}0.0083 * * * \\
(3.28)\end{array}$ & $\begin{array}{l}0.0054^{* *} \\
(2.06)\end{array}$ & & $\begin{array}{l}0.0010 \\
(0.30)\end{array}$ & $\begin{array}{l}-0.0024 \\
(-0.79)\end{array}$ & & $\begin{array}{l}0.0121 \\
(1.48)\end{array}$ & $\begin{array}{l}-0.0025 \\
(-0.59)\end{array}$ \\
\hline$\Delta$ Beta $^{2}$ & & & $\begin{array}{l}0.0027 \\
(0.61)\end{array}$ & & & $\begin{array}{l}-0.0122 \\
(-1.71)\end{array}$ & & & $\begin{array}{l}0.0151 \\
(1.65)\end{array}$ \\
\hline$\Delta$ Illiq & & $\begin{array}{l}0.0003 \\
(0.14)\end{array}$ & $\begin{array}{l}-0.0002 \\
(-0.07)\end{array}$ & & $\begin{array}{l}0.0049 \\
(1.39)\end{array}$ & $\begin{array}{l}0.0037 \\
(1.03)\end{array}$ & & $\begin{array}{l}0.0289 \\
(2.39)\end{array}$ & $\begin{array}{l}0.0607 * \\
(3.54)\end{array}$ \\
\hline$\Delta$ Illiq $^{2}$ & & & $\begin{array}{l}0.0041 \\
(0.80)\end{array}$ & & & $\begin{array}{l}0.0141 \text { ** } \\
(2.88)\end{array}$ & & & $\begin{array}{l}0.0446 \\
(1.63)\end{array}$ \\
\hline$\Delta \mathrm{Mom}$ & & $\begin{array}{l}-0.0012 \\
(-0.34)\end{array}$ & $\begin{array}{l}-0.0010 \\
(-0.28)\end{array}$ & & $\begin{array}{l}0.0006 \\
(0.15)\end{array}$ & $\begin{array}{l}-0.0070 \\
(-1.56)\end{array}$ & & $\begin{array}{l}0.0032 \\
(0.84)\end{array}$ & $\begin{array}{l}0.0043 \\
(0.83)\end{array}$ \\
\hline$\Delta \mathrm{Mom}^{2}$ & & & $\begin{array}{l}0.0076 \\
(1.21)\end{array}$ & & & $\begin{array}{l}0.0059 \\
(1.33)\end{array}$ & & & $\begin{array}{l}-0.0067 \\
(-0.22)\end{array}$ \\
\hline$\Delta \mathrm{IVOL}$ & & $\begin{array}{l}-0.0021 \\
(-0.77)\end{array}$ & $\begin{array}{l}-0.0024 \\
(-0.88)\end{array}$ & & $\begin{array}{l}-0.0071 \\
(-1.60)\end{array}$ & $\begin{array}{l}0.0002 \\
(0.04)\end{array}$ & & $\begin{array}{l}-0.0210^{*} \\
(-3.68)\end{array}$ & $\begin{array}{l}-0.0269 \\
(-2.94)\end{array}$ \\
\hline$\Delta \mathrm{IVOL}^{2}$ & & & $\begin{array}{l}0.0041 \\
(1.02)\end{array}$ & & & $\begin{array}{l}-0.0001 \\
(-0.02)\end{array}$ & & & $\begin{array}{l}0.0089 \\
(1.62)\end{array}$ \\
\hline $\mathrm{N}$ & 1,264 & 1,264 & 1,264 & 524 & 524 & 524 & 144 & 144 & 144 \\
\hline Adjusted $\mathrm{R}^{2}$ & 0.000 & 0.002 & 0.003 & 0.000 & 0.000 & 0.001 & 0.000 & 0.043 & 0.034 \\
\hline Wealth Relative & 0.98 & 1.01 & 0.78 & 0.89 & 0.93 & 0.91 & 1.04 & 1.40 & 1.11 \\
\hline
\end{tabular}




\section{Table 13}

\section{Difference-in-differences regression for non-U.S. bank M\&As}

This table summarizes the difference-in-differences (DD) regression results for a sample of 195 completed nonU.S. bank mergers announced between 1990 and 2014. The dependent variable in each regression is the bidder, target or combined three-day CARs centered on the announcement day. Non-U.S. represents the full sample, where both bidders and targets are non-U.S. firms. EU represents the sub-sample where both bidders and targets are located in the EU-15 plus Norway and Switzerland. In each regression, we include the same control variables as in Table 4. All independent variables are defined in the Appendix. All continuous variables are winsorized at $2 \%$ and $98 \%$ level. Heteroskedasticity-robust $t$-statistics are reported in parentheses. The symbols $*, * *$, and $* * *$ denote statistical significance at the $0.10,0.05$ and 0.01 levels, respectively, using a 2 -tail test.

\begin{tabular}{|c|c|c|c|c|c|c|}
\hline \multirow[b]{2}{*}{ Variables } & \multicolumn{2}{|l|}{ Bidder } & \multicolumn{2}{|l|}{ Target } & \multicolumn{2}{|l|}{ Combined } \\
\hline & Non-U.S. & EU & Non-U.S. & EU & Non-U.S. & EU \\
\hline Constant & $\begin{array}{l}-0.083^{*} \\
(-1.81)\end{array}$ & $\begin{array}{l}-0.084 \\
(-1.33)\end{array}$ & $\begin{array}{l}0.203 \\
(1.51)\end{array}$ & $\begin{array}{l}0.832 * * * \\
(3.05)\end{array}$ & $\begin{array}{l}-0.024 \\
(-0.78)\end{array}$ & $\begin{array}{l}-0.024 \\
(-0.50)\end{array}$ \\
\hline DFA & $\begin{array}{l}0.007 \\
(0.61)\end{array}$ & $\begin{array}{l}0.008 \\
(0.43)\end{array}$ & $\begin{array}{l}0.078^{*} \\
(1.88)\end{array}$ & $\begin{array}{l}0.057 \\
(0.48)\end{array}$ & $\begin{array}{l}0.005 \\
(0.54)\end{array}$ & $\begin{array}{l}0.008 \\
(0.47)\end{array}$ \\
\hline Small & $\begin{array}{l}0.024 \\
(1.07)\end{array}$ & $\begin{array}{l}0.069 * \\
(1.85)\end{array}$ & $\begin{array}{l}-0.033 \\
(-0.78)\end{array}$ & $\begin{array}{l}-0.194 * * \\
(-2.37)\end{array}$ & $\begin{array}{l}-0.006 \\
(-0.34)\end{array}$ & $\begin{array}{l}0.013 \\
(0.65)\end{array}$ \\
\hline DFA·Small & $\begin{array}{l}-0.007 \\
(-0.32)\end{array}$ & $\begin{array}{l}-0.035 \\
(-0.97)\end{array}$ & $\begin{array}{l}-0.045 \\
(-0.74)\end{array}$ & $\begin{array}{l}0.063 \\
(0.41)\end{array}$ & $\begin{array}{l}0.025 \\
(1.21)\end{array}$ & $\begin{array}{l}0.031 \\
(1.13)\end{array}$ \\
\hline Control Variables & Yes & Yes & Yes & Yes & Yes & Yes \\
\hline $\mathrm{N}$ & 195 & 94 & 195 & 94 & 195 & 94 \\
\hline Adjusted $\mathrm{R}^{2}$ & 0.033 & 0.042 & 0.115 & 0.205 & 0.004 & 0.011 \\
\hline
\end{tabular}

